\title{
Thirty years of genetic progress combined with seed ethylene priming improved drought resistance of wheat through long- term drought stress memory
}

\section{Hongkun Yang}

Sichuan Agricultural University

Wenmei Hu

Sichuan Agricultural University

Jiarong Zhao

Sichuan Agricultural University

Xiulan Huang

Sichuan Agricultural University

\section{Ting Zheng}

Sichuan Agricultural University

Gaoqiong Fan ( $\sim$ fangao20056@126.com)

Sichuan Agricultural University https://orcid.org/0000-0003-0772-205X

\section{Research Article}

Keywords: Winter wheat, Seed ethylene priming, Drought avoidance, Drought tolerance

Posted Date: April 1st, 2021

DOI: https://doi.org/10.21203/rs.3.rs-380527/v1

License: (c) (1) This work is licensed under a Creative Commons Attribution 4.0 International License. Read Full License 


\section{Abstract}

Knowledge of short-term physiological adaption of wheat to soil water deficit is well understood, but little is known about seed ethylene priming effect on long-term drought stress memory of dryland winter wheat. The 42 leading and new cultivars released between 1992 to 2017 were subjected to drought (45\% Field water-holding capacity), and well-watered (75\% Field water-holding capacity) conditions aim to screen cultivars with contrasting drought resistance and grain yield. Seeds primed with ethylene were subjected to both PEG-8000 and pure water to uncover ethylene-induced stress memory at both physiological and organ levels. Results showed that the soil water deficit ( $45 \% \mathrm{FC})$ that occurred at the tillering stage resulted in $3.2 \%$ to $67.4 \%$ yield loss for 42 cultivars, which was determined mainly by the decrease in the fertile spike. Seed ethylene priming maintained leaf water by reducing root volume and dry weight, which played a crucial role in drought avoidance. Seed ethylene priming decreased malondialdehyde content by regulating auxin and abscisic acid signaling, reactive oxygen species scavenging capability, and osmotic regulation, which plays a crucial role in drought tolerance. Seed ethylene priming improved drought tolerance of the wheat through metabolic modification of carbon metabolism, glutathione metabolism, and phenylpropanoid biosynthesis. The seed ethylene priming induced long-term stress memory that improved tillering capacity and reduced wheat spikelets abortion, which provided extra $0.3 \mathrm{t}$ ha -1 of grain yield. These results suggested that seed ethylene priming allowed the recall of long-lasting stress defensive memory, increasing grain yield by both drought avoidance and drought tolerance.

\section{Introduction}

The monitoring of global climate changes indicated that extreme climate events occurred more frequently and in more severity (IPCC 2016). Globally, a series of studies published from 1980 to 2015 have shown that the drought leads to $21-40 \%$ yield reduction in wheat, and the severity and duration of the drought determine the extent of yield loss (Daryanto et al. 2017; Fahad et al. 2017). Though all wheat stages could be affected by drought stress, the tillering and grain-filling are more susceptible than other wheat-growing stages, and the soil water deficit that occurred at tillering will cause an unrecoverable reduction in ear-bearing tillers and grain yield (Farooq et al. 2014). The direct grain yield loss by soil water deficit is up to 48.9 million tons as the soil water deficit will affect the soil water and root relation at all levels from molecular, cellular metabolic events and organs to the whole plant (Muscolo et al. 2015). Preventing such high yield loss is particularly crucial to address the challenges of climate change.

Drought avoidance and drought tolerance are the dominant approaches for drought resistance conferred by crops than drought escape, and the drought resistance is associated with physiology and biochemical responses at molecular, cellular, tissue, organ, and whole plant levels (Fang and Xiong 2015; Li et al. 2021). Plants adapt to soil water deficit at the whole plant level by generating a more in-depth root system, smaller leaves, and rolling of leaves for reducing leaf water loss (Liu et al. 2006). To survive under extreme soil water deficit when the plant cannot avoid it, the plants have evolved sophisticated mechanisms to alleviate organelle damage when they perceive the signal of environmental deterioration. At the cellular level, the soil water deficit impairs plant growth mediated by overproduction of reactive oxygen species (ROS) resulted in peroxidation of the cell membrane, thereby caused leakage of cell metabolites and degradation of enzyme proteins (Li and Liu 2016; Miller et al. 2010). Consequently, at the organic level, the drought stress led to leaf water loss (Egea et al. 2018), decreased plant photosynthesis, plant biomass, and final grain yield (Pinheiro and Chaves 2011). The drought tolerance has been reported to rely mainly on reactive oxygen species (ROS) scavenging enzymes, osmotic adjustments, and stomatal regulation. The ROS scavenging mediated by both enzymatic and non-enzymatic antioxidant defense systems ensures that the production and removal of free radicals in plants are balanced (Sairam and Saxena 2000; Abid et al. 2017). The osmotic adjustments reduce organelle damage by maintaining leaf water content under soil water deficit conditions (Ashraf 2010; Wang et al. 2019). The root to leaf ABA signal is the crucial factor for stomatal regulation that ensures the stomatal $\mathrm{CO}_{2}$ exchanges and leaf water loss in a balanced state (Tombesi et al. 2015). At the molecular level, these defense mechanisms have been reportly modulated by the transcription factors and phytohormone signal transduction pathways, which further regulate root osmolyte levels by triggering sugar catabolism, regulating stomatal closure by transducing root to leaf $A B A$ 
signaling, increasing cell antioxidants level by activating the ROS defense system (Wang et al. 2021; Harb et al. 2020; Li et al. 2019). Although the short-term adaption of plants to drought stress has been clarified, the knowledge of long-term drought stress memory is more valuable for avoiding final grain yield loss by soil water deficit.

Previous exposure to abiotic stress can affect subsequent physiological responses and eventually prepare plants to respond more quickly and actively to future stress pressures (Wang et al. 2019; Abid et al. 2018). Seed hormonal priming is pre-sowing partial hydration of seeds with hormones without allowing radicle emergence, which has proved to be an effective method in imparting stress tolerance to plants (Jisha et al. 2013; Abid et al. 2018). Seed priming induces stress memory that was mediated by a coordinated reaction at organismal, cellular, and genome levels (Virlouvet and Fromm 2015). This memory is always accompanied by plant growth, even inherited by the next generation (Abid et al. 2018; Kinoshita and Seki 2014). Ethylene (Eth) is a phytohormone directly associated with plant growth and abiotic stress responses due to its role in activating defense responses and reducing the damaging effect of various abiotic stress (Kolbert et al. 2019). It is widely acknowledged that the Eth regulates many developmental and physiological processes such as cell division, root growth, anthocyanin accumulation, and embryogenesis (Divte et al. 2019). The endogenous Eth level was enhanced in many species when plants received environmental deterioration, such as cold stress, soil water deficit, and increased salinity (Kemal 2015). However, the seed ethylene priming effect on long-term stress memory and final grain yield remains unclear.

Our previous results have clarified the genetic yield gain in a historical set of cultivars released between 1965 to 2017 in Southwest China. In this study, the 42 cultivars were subjected to drought and well-watered conditions to identify the critical drought avoidance traits for enhancing drought resistance in the future. The seeds ethylene priming was used to evaluate short-term physiological adaption and long-term drought stress memory of wheat plants to enhance drought tolerance for sustainable yield production in an increasingly changing environment. Comparative root hair transcriptome analysis is conducted to understand the underlying mechanism of seed ethylene-mediated drought tolerance. The current study was conducted based on the hypothesis that seed ethylene priming allowed recalling the long-term drought stress memory that improves drought resistance of the wheat by multi-phytohormone cross-talk, ROS scavenging capability, and metabolic alterations, thereby reducing leaf water loss and increasing final grain yield.

\section{Materials And Methods}

\subsection{Plant material and experimental design}

The field trials were carried out at Wenjiang Experimental Station $\left(29^{\circ} 51^{\prime} \mathrm{N}, 104^{\circ} 12^{\prime} \mathrm{E}\right)$ of Sichuan Agriculture University. The experimental site's soil is a typical purple lithomorphic soil as per FAO soil taxonomy (Shi et al. 2006). A consecutive 22 years (19972019) climate data showed that the accumulative rainfall from wheat seed sowing to the time of harvest at the experimental site ranged from $123 \mathrm{~mm}$ to $203 \mathrm{~mm}$, and spread unevenly over the years. The dry climate frequently occurred in wheat tillering, and the extreme droughts are becoming more severe in recent decades (Yang et al. 2020). Thus, the experiments with cultivars were carried out with contrasting drought resistance and seed priming treatments under both well-watered and drought conditions.

During the 2016-2017 and 2017-2018 cropping seasons, 42 leading and new cultivars released between 1965 and 2018 were collected from 9 breeding institutions, and it was selected to represent the 51 years of past genetic gain in grain yield and drought tolerance in Southwestern Wheat Production Region of China (supplemental file 1)(Zhou et al. 2007). The 42 leading and new cultivars were subjected to the water-deficit ( $45 \pm 5 \%$ field water holding capacity) and well-watered conditions ( $75 \% \pm 5 \% \mathrm{FC}$ ), respectively, to investigate how newly released cultivars adapted to drought stress in an increasingly variable climate. After screening the breakthrough cultivars with high yield and drought resistance, the seeds of drought-sensitive cultivar were primed with ethylene to enhance the wheat's drought resistance. The ethylene was applied for the treatments because the seeds primed with $200 \mathrm{mg} \mathrm{kg}$

${ }^{1}$ ethylene increased both the grain yield and drought resistance significantly more than other treatments (Table 2). In short, the 
wheat seeds were sterilized with $200 \mathrm{mg} \mathrm{kg}^{-1}$ ethylene for $10 \mathrm{~h}$ and then rinsed three times with distilled water prepared for seed ethylene priming, and the seeds presoaked with distilled water were taken as the control. After priming, the seeds for both treatments were washed with distilled water and then re-dried near to their original weight with forced air at $27 \pm 3{ }^{\circ} \mathrm{C}$ under shade. The seeds were sown in the soil maintained at $75 \%$ FC (well-watered) and 45\% of FC (drought) until the end of wheat jointing using an equitensiometer and automatic irrigation system to control the soil water content. Finally, four treatments were formed: unprimed seedlings grown at water sufficient condition (E0P0), unprimed seedlings grown at water deficit condition (E0P1), primed seedlings grown at water sufficient condition (E1P0), and primed seedling grown at water deficit condition (E1P1), respectively. To reduce the random effect caused by the soil environment when investigating different expressed genes response to soil water deficit, the PEG8000 applicated because it is better than low molecular weight PEG for simulating soil drought (Kumar et al. 2019). Therefore, both primed and unprimed seedlings ( 2 weeks old) were subjected to $20 \%$ (v/v) PEG8000 in the growth cabinet at $25^{\circ} \mathrm{C}$ for two weeks with $13 \mathrm{~h}$ of light and $11 \mathrm{~h}$ of darkness in $24 \mathrm{~h}$ period. Each sample's root hairs were collected at $1 \mathrm{~h}$ and 12 after treatment and then stored at $-80^{\circ} \mathrm{C}$ prepared for RNA-sequencing (RNA-seq) analysis to clarify the short-term physiological mechanism of primed and unprimed plants adapt to drought (45\% FC). Consecutive 15 wheat plants were collected at $24 \mathrm{~h}$ and 9 days after imposing $20 \%$ (v/v) PEG8000, prepared for the observations of plant hormones, antioxygen enzymes, and osmotic adjustment substance. The yieldassociated traits were determined at maturation to clarify the long-term stress memory effect on the final yield loss by drought.

\subsection{Sampling and Lab analyses}

\subsubsection{Yield loss by soil water deficit}

The fertile spikes, the number of grains per panicle, and the 1000-kernel weight were determined for calculating grain yield for each treatment at $13.5 \%$ moisture content. The number of the spikes in a representative plot of $1 \mathrm{~m}^{2}$ were counted, and their grains were collected, air-dried, and then threshed for seed moisture determination using a digital moisture tester (DMC-700, Seedburo, Chicago, IL, USA). The grain number per ear was measure by counting the grains of consecutive 30 wheat plants. The air-dried grains were used to measure $1000-$ kernel weight. The yield loss by soil water deficit was calculated as follows: $\mathrm{Y}_{\text {loss }}=\left(\mathrm{Yc}_{\mathrm{c}} \mathrm{Yd}\right) \times 100 / \mathrm{Yc}$, where the Yc and Yd represent the yield of control and drought stress treatments, respectively.

\subsubsection{Root morphology traits, plant biomass, and flag Leaf water loss}

Fifteen consecutive wheat plants were randomly collected using the soil core method (Bohm 1979). The collected root samples were soaked in $1 \mathrm{M} \mathrm{NaCl}$ for $16 \mathrm{~h}$ to remove soil aggregates and then washed with a hydropneumatic washing machine. After the remaining mineral particles and organic debris were removed, the root samples were rinsed and then placed in the distilled water. The root morphology characteristics, including total root length, root surface area, root diagram, root volume, and the number of root tips, were recorded digitally using a flatbed scanner (Epson Expression 1600XL-Pro), and these parameters were estimated using the WinRHIZO root analysis software (WinRHIZO, Regent Instruments, Canada).

According to a previous protocol, the root system vigor of collected hairy roots was stained at room temperature for $24 \mathrm{~h}$ in 1mol/L phosphate buffer solution containing 1\% triphenyl tetrazolium chloride (Li et al. 2016). After the sample was washed in distilled water, it was homogenized in ethyl acetate and then centrifuged at 5000×g for 10 min at $4^{\circ} \mathrm{C}$. The supernatant homogenate was assayed immediately at $485 \mathrm{~nm}$, and the overall root system vigor was expressed as mg benzophenone hydrazine (TTCH) generated from each gram of fresh soil per hour (mg TTCH g-1 $\mathrm{FW} \mathrm{h}^{-1}$ ).

A consecutive 15 plants were collected at the wheat tillering in each plot and then separated into leaf, stem, and root. The aboveground plant biomass was measured by the oven-drying method. The relative leaf water content was calculated as the decrease 
percentage of leaf water in soil water deficit treatments compared with well-watered condition (Wang et al. 2019) using the following

equation: $\quad R W C(\%)=\frac{F W-D W}{T M-D M} \times 100$, in which FW refers to fresh weight for those plants primed with Ethylene, TW refers to dry weight for those plants without priming, and the DM refers to the dry weight of oven-dried leaves at $75^{\circ} \mathrm{C}$ till constant weight.

\subsubsection{Endogenous hormones of root hairs}

The root hairs were collected and then frozen in liquid nitrogen immediately and stored at $-80^{\circ} \mathrm{C}$ until analysis. The collected root hairs (1g) were homogenized in $5 \mathrm{ml}$ of cold $80 \%$ aqueous methanol overnight at $4{ }^{\circ} \mathrm{C}$ and then centrifuged at $10,000 \times \mathrm{g}$ for $20 \mathrm{~min}$ at $4{ }^{\circ} \mathrm{C}$. After the crude extract liquid was purified by passing a C18 Sep-Pak Catridge, a 400ul of extract solution was condensed using an $\mathrm{N}_{2}$ and then re-dissolved in $400 \mathrm{ul}$ phosphate buffer $(0.01 \mathrm{~mol} / \mathrm{L}, \mathrm{pH} 7.4)$ prepared for phytohormones analysis. The indole-3-acetic acid (IAA) content was determined as following Tian et al. (2008). The gibberellin $\left(\mathrm{GA}_{1}\right.$ and $\left.\mathrm{GA}_{3}\right)$ content was carried out using a previously described method (Castillo and Martinez 1997). Extraction and assay of ABA were conducted as described previously (Lang et al. 2018).

\subsubsection{Membrane lipids peroxidation, antioxidation enzymes, and osmotic adjustment substance assays}

The oxidative damage to the membrane lipids was estimated by malondialdehyde (MDA), a major thiobarbituric acid, as an indicator for membrane peroxidation (Wei et al. 2016). The fully expanded leaves (0.2 g) were ground in $5 \mathrm{~mL}$ of $95 \%$ (v/v) trichloroacetic acid (TCA), and the homogenate was centrifuged at 15,000 $\times \mathrm{g}$ for $10 \mathrm{~min}$ at $4{ }^{\circ} \mathrm{C}$. An equal volume of supernatant and $0.6 \%(\mathrm{w} / \mathrm{v})$ thiobarbituric acid was added to the TCA (20\%), followed by heating the solution at $96{ }^{\circ} \mathrm{C}$ for $30 \mathrm{~min}$. The MDA concentration was measured by recording $450 \mathrm{~nm}, 532 \mathrm{~nm}$, and $600 \mathrm{~nm}$ using the formula: $\mathrm{C}=6.45 \times\left(\mathrm{OD}_{532}-\mathrm{OD}_{600}\right)-0.56 \times \mathrm{OD}_{450}$, and the MDA content was expressed as $\mathrm{mol} \mathrm{g}^{-1} \mathrm{FW}$.

The enzyme activities of SOD, POD, and CAT were extracted and assayed as per the previous protocol (Wang et al. 2019) with minor modifications. The frozen leaf tissue $(0.3 \mathrm{~g})$ was ground in $5 \mathrm{~mL}$ of $0.1 \mathrm{M}$ Tris-HCl buffer (pH=7.8) containing $1 \mathrm{mM}$ DTT, $1 \mathrm{mM}$ EDTA and $1 \%$ PVP. The homogenate was centrifuged at $20,000 \times \mathrm{g}$ for $20 \mathrm{~min}$ at $4{ }^{\circ} \mathrm{C}$. The supernatant was collected for measuring enzyme activities. Superoxide dismutase (SOD, EC 1.15.1.1) activity was assayed by monitoring the inhibition of photochemical reduction of nitro blue tetrazolium. Catalase (CAT, EC 1.11.3.6) activity was assayed by potassium permanganate titration and expressed as $\mathrm{M} \mathrm{H}_{2} \mathrm{O}_{2} \mathrm{~g}^{-1} \mathrm{FW} \mathrm{min}^{-1}$. Peroxidase (POD, EC 1.11.1.7) activity was estimated as the guaiacol oxidation rate by measuring the rate of change in absorbance at $436 \mathrm{~nm}$.

The amount of free proline was extracted from fresh flag leaves of the wheat, and it was measured by using the ninhydrin reagent as following the method of Wang et al (2019) with minor modification. After the leaves were ground in $5 \mathrm{~mL}$ of $3 \%$ (w/v) sulfosalicylic acid, the homogenate was centrifuged at $15,000 \times \mathrm{g}$ for $10 \mathrm{~min}$ at $4{ }^{\circ} \mathrm{C}$. The collected supernatant was re-extracted with $2 \mathrm{ml}$ toluene20, and the absorbance was recorded at 520nm. The free proline was expressed as mmol proline $\mathrm{g}^{-1} \mathrm{FW}$

The total water-soluble carbohydrates (WSC) were determinate by the anthrone method (Yang et al. 2017). In brief, $0.1 \mathrm{~g}$ dry leaf powder was extracted three times, with $80 \%$ ethanol, in a water bath at $80^{\circ} \mathrm{C}$ for 30 min. The non-structural carbohydrates were diluted to a final volume of $25 \mathrm{~mL}$, and the non-structural carbohydrates were measured spectrophotometrically at 620 nm using an anthrone reagent.

\subsubsection{Transcriptome profiling of wheat root hair cell}


RNA extraction, cDNA library construction, and RNA sequencing: In each plot, the total RNA from root hairs was extracted using Trizol reagent (Invitrogen, Carlsbad, CA) and purified using Total RNA Kit (Qiagen, Valencia, CA) according to the instructions of the manufacturer. The RNA concentration and absorption curves were checked using a NanoDrop 2000 spectrophotometer (ND-2000, Thermo Fisher Scientific, Inc., USA). The RNA integrity number values were assessed on a Bioanalyzer 2100 (Alignment, Santa Clara, CA), and integrity number values were more significant than 9 for all total RNA samples. Sequencing libraries with an average insert size of 200 bp were prepared with TruSeq RNA Sample Preparation Kit v2 (Illumina, San Diego, USA) and sequenced on HiSeq2000 (Illumina, San Diego, USA) according to the manufacturer instructions (Illumina, San Diego, CA). In short, the Poly-A-containing mRNA was purified twice from the total RNA using poly-T oligo-attached magnetic beads. First-strand cDNA was generated using reverse transcriptase and random primers. Following the second strand cDNA synthesis and adaptor ligation, 200-bp cDNA fragments were isolated using gel electrophoresis and amplified by 18 cycles. The products were loaded onto an Illumina HiSeq2000 instrument and subjected to 100 cycles of paired-end $(2 \times 100 \mathrm{bp})$ sequencing. The processing of fluorescent images into sequences, base-calling, and quality value calculations were performed using the Illumina data processing pipeline (version 1.8).

Gene ontology and pathway enrichment of DEGs: The high-quality reads were obtained by removing low-quality reads (Q < 20), and then mapped onto the international wheat genome sequencing consortium (IWGSC) using Bowtie2 (v2.2.9). The differential expression level was estimated using $\mathrm{R}$ software with edgeR package ( $\mathrm{R}$ version: 4.0, edgeR version: 2.3.52). A strict algorithm was developed to identify differentially expressed genes (DEGs) between samples, and false positive and false negative errors are performed using Benjamini and Yekutieli hypergeometric test (FDR) method (Wei et al. 2020). Expression levels that exhibited an absolute $\log 2(\mathrm{FC}) \geq 1$ and an absolute $-\log 10(\mathrm{P}) \geq 1.41$ as the threshold to be significantly differentially expressed genes (DEGs). Two-fold up-or down-regulation compared to the corresponding control condition were taken only into consideration for further analysis. Gene Ontology (GO) enrichment was based on AgriGO software with a hypergeometric statistical test and Hochberg (FDR). Pathway enrichment analysis of DEGs was performed using the Kyoto Encyclopedia of Genes and Genomes (KEGG, http://www.genome.jp/kegg/). This analysis identifies enriched signals transduction pathways and metabolic pathways in DEGs compared with the whole genome background.

Validation of differentiated expressed genes by qRT-PCR: Total RNA for each sample was pretreated with DNase I, and the firststrand cDNA was generated using a RevertAid First Strand cDNA Synthesis kit (Fermentas, Vilnius, Lithuania) with oligo (dT) 20 primer following manufacturer instructions. The SYBR-based qRT-PCR reactions (SYBR Green I, Osaka, Japan) were performed in a $10 \mu \mathrm{l}$ reaction volume on a Light Cycler 480 system (Roche, Basel, Switzerland) using the following reaction conditions: $95^{\circ} \mathrm{C}$ for 1 min followed by 40 cycles of $95^{\circ} \mathrm{C}$ for $10 \mathrm{~s}$ and $60^{\circ} \mathrm{C}$ for $15 \mathrm{~s}$. The detection threshold cycle for each reaction was normalized against the housekeeping gene expression level with primer sequences 5'-GACCGTATGAGCAAGGAGAT-3' and 5'-CAATCGCTGGACCTGACTC$\left.3^{\prime}\right)$. All qRT-PCR reactions were replicated three times, and the results were analyzed based on the $\Delta \Delta C T$ method (Roche), where $\Delta \Delta \mathrm{CT}$ represents $\Delta \mathrm{CT}$ condition of interest $-\Delta \mathrm{CT}$ control. The results obtained were transformed to a $\log _{2}$ scale.

\subsection{Statistical analysis}

Two-way ANOVA was applied to analyze the difference between treatments performed using SAS version 9.1.3 (Statistical Analysis System, Institute INC, Box 8000, Cary, North Carolina 27511, USA). A significant level was identified at the 0.05 probability level by the LSD test. Graphs were plotted by using the Origin software, version 9.0. 


\section{Results}

3.1 Drought sensitivity analysis of 42 leading and new cultivars released between 1965 to 2017

The soil water deficit ( $75 \% \mathrm{FC}$ ) resulted in 42 cultivars' grain yields decreased by between $3.2 \%$ and $67.4 \%$, compared with those under well-watered conditions. The higher grain yield observed under well-watered conditions indicated a more significant yield loss rate by soil water deficit (Fig 1A). The first two principles explained the $26.7 \%$ and $15.3 \%$ of the yield variations, where cultivars with PC1 scores $>0$ identified as high-yielding cultivars; PC2 scores $>0$ identified as higher drought resistance cultivars. The PCA1 mainly relates to root length, chlorophyll content, and leaf area, while PCA2 mainly relates to root length, chlorophyll content, leaf water loss, and yield loss. The loading scores combined with the relative contribution to the sum of squares revealed that the yield loss attributed mainly to fertile spikes and panicle weight (Fig1, Table 1). Cultivars derived the negative relationship between grain yield and yield loss rate to identify drought avoidance traits. The droughttolerant group includes five cultivars that showed both high yield and drought resistance. The drought sensitivity group consists of seven cultivars with a low yield and higher yield loss rate when the wheat is grown in 45\% FC compared with those grown under well-watered conditions (75\% FC). The drought sensitivity (CM-16), intermediate (CM-51), and tolerance (CM) cultivars with similar genetic backgrounds were screening from PCA biplot (Fig 1B). There was a dramatic decrease in plant biomass by soil water deficit (45\% FC) for the drought-sensitive cultivar (CM-104), while the drought-tolerant cultivars (CM-16) did not show a significant difference in the plant biomass compared with those well-watered plots (75\% FC). The yield components confirmed that the yield loss by soil water deficit could be attributed mainly to the decrease in fertile spikes and less by grains number per spike (Fig $1 \mathrm{C}$ ).

\subsection{Seed ethylene priming effect on yield associated wheat phenotypes}

Seed ethylene priming increased grain yield mainly by fertile spikes $(P<0.05$, Table 2$)$, and there were no significant differences in plant height, grain number per panicle, and 1000-kernel weight ( $P>0.05)$. The seed ethylene priming decreased the degraded spikelets by $24.2 \%$ compared with unprimed plants, and there was no significant difference for fertile spikelets. Seed ethylene priming increased tillering capacity by $21.5 \%$, and the tiller survival rate increased by $14.7 \%$, compared with those without seed ethylene priming. These results suggest that seed ethylene priming increased grain yield mainly by the fertile spike that was resulted from the increased tillering capacity and tiller survival rate.

3.3 Seed ethylene priming effect on root morphology traits and shoot biomass under soil water deficit

The soil water deficit resulted in root length, surface area, and root volume decreased by averages of $39.3 \%, 30.0 \%$, and $22.5 \%$, respectively, compared with those under well-watered conditions, whereas the root diagram increased $16.4 \%$ (Table 3 ). As a result of decreased root surface area, the soil drought (45\% FC) leads to the plant height, shoot dry weight, and leaf area per plant decreased by $31.4 \%, 37.6 \%$, and $62.7 \%$, respectively. In contrast, the seeds ethylene priming decreased leaf area reductions, shoot dry weight, and root dry weight, but not the plant height. Significant drought and priming interaction was observed in seedling heights and root to shoot ratio, but not the root surface area and shoot dry weight. These results suggested that seed ethylene priming improved plant resistance to soil water deficit by reduced root dry weight and LAI losses.

\subsection{Comparative phytohormones of root hairs and signal transduction pathways}

The unprimed plants grow on soil water deficit condition $(45 \% \mathrm{FC})$ lead to the root hair IAA, CTK, and $\mathrm{GA}_{1+3}$ contents decreased by an average of $8.5 \%, 17.9 \%$, and $15.4 \%$, respectively, as compared to the plant grown under well-watered condition (Fig 2). In contrast, the primed plant is grown at water deficit condition (45\%FC) lead to the IAA, CTK, and GA 3 contents decreased by an average of $18.1 \%, 26.6 \%$, and $29.4 \%$, respectively, as compared to the well-watered treatments. The primed plants grown at the soil water deficit condition have greater $A B A$ and ethylene contents than the unprimed treatments. These results suggested that plants primed with ethylene increased drought tolerance by increasing IAA, CTK, and GA 3 contents in early responses. 
The differently expressed genes related to drought stress response and ethylene mediated tolerance response revealed that the ABA and CTK signals were upregulated, including $P P 2 C, S n R K 2, B-A R R$, which further regulate stomatal closure and cell division. In contrast, the IAA signal including AUX1, AUX/IAA, GH3, and SAUR increased under soil drought, which further suppressed plant growth. Ethylene mediated drought tolerance associated with plant hormone signal was associated with Ethylene, IAA, and ABA signal pathways because the jasmonate ZIM domain (JAZ), ethylene response factor 1 (ERF-1) were down-regulated, and SAUR were upregulated response to enhanced drought tolerance. The above findings demonstrate that the ethylene-mediated drought tolerance relies on diverse signal pathways, including upregulated IAA signal transduction and the down-regulated ABA, JA, and Ethylene mediated stress responses.

3.4 Root hair antioxidative enzymes, osmotic adjustment substance, and leaf water loss

ROS-scavenging enzymes' activities were further examined to clarify the underlying ethylene-mediated short-term physiological adaption to soil water deficit (Table 4). As expected, drought stress (45\%FC) leads to overproduction of the ROS, which caused lipid oxidation as shown in the MDA content, and there were significant increases in the activities of SOD, POD, and CAT in both primed and unprimed treatments as compared to the well-watered treatment (75\%FC). Compared with unprimed control, the primed plants showed lower CAT activity and soluble sugar content, whereas increasing the activity of SOD. There was a five-fold increase in both SOD activity and soluble sugars content between well-watered and soil drought stress treatments, whereas primed plants decreased soluble sugar by $12.7 \%$ compared with unprimed plants. The proline in primed plants increased by $3.2 \%$ compared with unprimed plants. The plants grown under soil water deficit conditions (45\% FC) led to $7.6 \% \sim 6.9 \%$ of leaf water loss and $1.2 \sim 2.0 \%$ of root water loss than those grown under well-watered conditions ( $75 \%$ FC). The seed ethylene priming did not affect root moisture but reduced leaf water loss and leaf water content compared with those unprimed plants. These results suggested that seed ethylene priming reduced leaf water loss under soil water deficit by modifying ROS scavenging enzymes and osmotic adjustment substances.

\subsection{Global gene expression of root hairs by transcriptome sequencing}

Both primed and unprimed plants were subjected to $8 \%$ PEG-8000 to simulate drought stress for $1 \mathrm{~h}$ and $12 \mathrm{~h}$ to evaluate the similarities and differences in both drought-induced and Ethylene-induced transcriptomes responsive effects. The experiment performed deep RNA sequencing of 1-week old wheat seedling leaves using the Illumina sequencing platform. After removing low-quality reads, the eight materials yielded 79.3 million to 148.5 million clean reads (see Methods, supplemental file 2). The high-quality reads accounted for more than $99.3 \%$ of the raw reads, and the Q30 for each sample was above $90.86 \%$. Clean reads of each sample were aligned with the reference genome, and the alignment efficiency ranged from $61.94 \%$ to $65.20 \%$. Fold Change $(>2)$ and FDR $<0.001$ were used as screening criteria for differentially expressed genes (DEGs). The controlled and drought-stressed groups were separated by the first principle component representing $56.7 \%$ of the total variation and the second principle representing 19.4\% of the total variance (Fig3 A). Drought stress-induced 3197 DEGs at 1 hour after subjected to drought stress compared with controlled, of which 1953 genes were upregulated, and 1244 genes were downregulated (Fig 3B). Seeds Ethylene priming induced 2586 DEGs, of which 1698 genes were upregulated and 888 genes were down-regulated. Both droughts induced DEGs and Ethylene induced DEGs at $12 \mathrm{~h}$ after treatments were significantly higher than that of at $1 \mathrm{~h}$ subjected to drought stress, of which 1744 and 2272 DEGs were upregulated, and 2743 and 2711 DEGs were down-regulated. The Venn diagram plot showed that there were 642 and 1779 genes associated with drought tolerance in both $1 \mathrm{~h}$ and $24 \mathrm{~h}$ after subjected to drought stress, in which 730 unique genes were expressed after subjected to drought stress (Fig 3C). All the DEGs were analyzed for time-scale variation in their expression and were classified into 9 clusters (Fig 3D). The clustering analysis also allowed us to sort genes responses according to their overall behavior. This analysis has demonstrated that rapid gene response could be classified into up to 9 clusters. We identified 1479 genes that were consistently upregulated (cluster 1), and 1352 genes (cluster 9) were always down-regulated repose to drought stress. Seeds Ethylene priming induced 22 genes that consistently upregulated in root hairs. In contrast, the 19 genes that consistently down-regulated in root hairs. The chromosome-wise gene expression pattern revealed nearly the same expression pattern in $1 \mathrm{~h}$ and $24 \mathrm{~h}$ subjected to drought stress. DEGs associated with drought stress were mainly distributed on $\mathrm{Chr} 3 \mathrm{BL}(5 \%), \mathrm{Chr} 5$ 
BL (5\%), Chr5 DL (4\%), and Chr2 BL (4\%). In contrast, DEGs associated with Ethylene mediated drought tolerance were mainly distributed on Chr4 DS (6\%), Chr5 BL (6\%), and Chr3 B (5\%).

\subsection{Go and KEGG analysis of the differently expressed genes of root hairs}

Go enrichment analysis and were placed into three major categories: "biological process", "cellular components", and "molecular function"(Fig 4). The transcripts of EOPO vs. EOP1 related to drought stress response in the biological process category mainly involved metabolite process, cellular process, single organism process, response to the stimulus. The drought stress-induced DEGs in the cellular components category mainly expressed in the cell part, organelle, and membrane. The E0P1vs E1P1 related to Ethylene mediated drought tolerance that associated with increased gene expression in the cell wall $(9.67 \%$ vs. $11.76 \%)$, chloroplast ( $13.44 \%$ vs. $18.62 \%)$, and cytosol ( $8.60 \%$ vs. $10.78 \%)$, and decreased gene expression in Golgi apparatus ( $16.12 \%$ vs. $7.84 \%)$. The most enriched GO term under molecular function was catalytic activity, which was $21.02 \%$ and $17.89 \%$ in the EOP0 vs. EOP1 and EOP1 vs. E1P1 comparisons. The other GO terms under molecular function were binding, electron carrier activity, transporter activity, and nucleic acid binding transcription factor activity.

The pathway-based analysis was performed using the Kyoto Encyclopedia of Genes and genomes pathway database (Fig 5). The results showed that the drought stress-induced 3197 DEGs (1h) and 4487 DEGs (12h) involves 20 metabolites pathway and 17 functional pathways (Q-value $<1$ ). Most of the DEGs associated with drought stress-related to plant hormone signals, glucosinolate biosynthesis, taurine, and hypotaurine metabolism, zeatin glutathione metabolism, flavone, and flavonol biosynthesis. In the environmental information procession module, forty-six DEGs were enriched in the plant hormone signal transduction pathway, including 12 down-regulated genes related to auxin signal transduction, one upregulated gene related to zeatin auxin signal transduction, and two down-regulated genes connected to the ABA signal transduction pathway. The acid receptor PYR/PYL family were down-regulated; 13 genes encoding protein phosphatase $2 \mathrm{C}$ were upregulated; 1 gene encoding serine/threonine-protein kinase SRK2 was upregulated; 2 genes encoding ethylene response transcription factor were upregulated; 8 genes related to jasmonic acid signal transduction pathway were upregulated; and 8 genes encoding salicylic acid were upregulated. It was found that 100 differentially expressed genes were enriched in the glutathione metabolic pathway, in which three genes encoding glutamate-cysteine ligase were upregulated, six genes encoding glutathione reductase (NADPH) were upregulated, three genes encoding glutathione peroxidase were upregulated, and 85 genes encoding glutathione S-transferase were upregulated. Drought stress also induced 105 DEGs enriched in the phenylpropanoid biosynthesis pathways and 81 DEGs enriched in the phenylalanine metabolism pathways. A Total of 902 transcription factors were identified response to drought stress, and the top 5 leading transcription factors were RLKPelle_DLSV, MYB, RLK-Pelle_WAK, RLK-Pelle_LRR-I-1, and $\mathrm{C}_{2} \mathrm{H}_{2}$.

Carbon metabolism, carbon fixation, and phenylpropanoid biosynthesis were the top 3 crucial pathways associated with Ethylene mediated drought tolerance. The DEGs encode ribulose-bisphosphate carboxylase, glyceraldehyde-3-phosphate dehydrogenase (NADP+) glyceraldehyde-3-phosphate dehydrogenase were upregulated response to Ethylene mediated drought tolerance. The DEGs encoding peroxidase enriched in phenylpropanoid biosynthesis were a down-regulated response to Ethylene mediated drought tolerance. A total of 42 transcription factors were identified, which were associated with ethylene-mediated drought tolerance response, and the 3 top transcription factors were the RLK-Pelle_DLSV, NAC, and AP2/ERF-EPF.

\subsection{Validation of DEGs using qRT-PCR}

The qRT-PCR validation of the DEGs was performed using cDNA isolated from treatments. The selection of high up- and down-regulated genes was based primarily on regulating various pathways related to drought stress and ethylene mediated drought tolerance (Fig 6). Because the number of down-regulated genes was greater than that of upregulated genes in $12 \mathrm{~h}$ after subjected to soil drought, the experiment chose more downregulated genes for validation through qRT-PCR. The expression level of each selected DEG for both priming and drought stress treatment compared to the expression level indicated by its transcriptome sequencing data. The differential gene expression detected by qRT-PCR was consistent with the 
up-and down-regulation trends of gene expression obtained from transcriptome sequencing $\left(R^{2}=0.89 ; n=24\right)$. The results were indicating that the analytical results of transcriptome sequencing were reliable.

\section{Discussion}

\subsection{Genetic modification of drought avoidance traits combined with seed ethylene priming provided an extra $0.3 \mathrm{thm}^{-2} \mathrm{yield}^{\mathrm{h}}$}

The natural and artificial selection of cultivars with high yield and drought resistance processes numerous physiological and molecular mechanisms adapt to drought stress while realizing the potential yield (Liu and Qin 2021). Identifying and utilizing traits associated with drought tolerance and drought avoidance is the most effective measure for reducing leaf water loss and stress injury (Kamphorst et al. 2019; Pouri et al. 2019; Katuwal et al. 2020; Liu and Qin 2021). Notably, the higher the grain yield under well-watered conditions ( $75 \% \mathrm{FC}$ ), the more significant yield loss by soil water deficit ( $45 \% \mathrm{FC})$. It is possible that cultivars with increasing drought resistance indicating higher metabolic cost while the yield potential realization. The intrinsic properties of 42 leading and new cultivars acclimate to soil water deficit provided a prospect for drought tolerance improvement while yield realization. There is no doubt that wheat cultivars selected from well-watered conditions have little contribution to improving drought tolerance even through genetic gain in different wheat production regions. The breakthrough cultivars released in recent years have both yield and drought resistance provided insights for future improvements. The yield loss by soil water deficit was determined mainly by the decrease in fertile spike, and the drought persistence primarily relates to root length, root volume, leaf chlorophyll content, and leaf water loss rate, which plays a significant role in drought avoidance. Plants that avoid drought stress rely on maximizing root surface area, minimizing leaf area, and decreasing leaf water loss (Fang et al. 2017; Sadok and Schoppach 2019; Pace et al. 2015). High leaf water content has been associated with higher leaf photosynthesis levels, cell membrane stability, ROS-savaging enzymes, and grain yield (Wang et al. 2021; Larkunthod et al. 2018). Although deeper root exploration may enhance water absorption in droughtstressed conditions, the metabolic cost cannot compensate for the loss of aboveground plant growth. Similarly, small leaf and prolonged stomatal closure increased the capability of drought avoidance, but in the long run, it may lead to a significant reduction in grain yield ( $\mathrm{Li}$ et al. 2021). Therefore, a further increase in root length is not a wise approach for both grain yield

and drought resistance because it will cause a decrease in carbon economy at the whole-plant scale. A novel finding from the present study is that the seed Ethylene priming enhanced both root volume and shoot dry weight without further metabolic cost on the deeper root. The drought resistance conferred by crops with increased root volume that improved tillering capability and spikelet survival rate and provided extra $0.3 \mathrm{t} \mathrm{hm}^{-2}$ grain yield under soil water deficit conditions (45\% FC).

\subsection{Seed ethylene priming recalling long-lasting stress memory through an altering signaling pathway}

Drought tolerance involves mechanisms operating at temporal scales, from short-term physiological feedback process, plants maintain leaf water, and long-term feedback strategies have participated in the trade-off between carbon accumulation and risks of deleterious soil water depletion. For most short-term physiological processes, the short-term (1h, $12 \mathrm{~h})$ response is involved in changes in stomatal control, hydraulic tissue conductance, osmotic adjustment, root-to-leaf growth response optimization of carbon metabolism (Tardieu et al. 2018). As expected, the ethylene-responsive factors 1 and 2 were downregulated at both $1 \mathrm{~h}$ and $12 \mathrm{~h}$ subject to drought stress, and the EIN 3 was upregulated compared with those grown under well-watered conditions. These results can be attributed to the ethylene-responsive factor (ERF) function involved in diverse plant reactions to biotic or abiotic stresses (Seo et al. 2010). ETR, EIN2, and EIN3 in soybean (Arraes et al. 2015), PYL in cotton (Liang et al. 2017), and JAR1 and MYC2 in soybean (Takagi et al. 2016) were reported to be positively correlated with drought tolerance. Seed ethylene priming allowed the recall of long-lasting stress defensive memory, which decreased the Ethylene perception signal's gene expression. The Ethylene perception signal and root to shoot ABA secondary signal involve a dialogue between $A B A, I A A$, and $S A$, and the $A B A$ is the dominant hormone regarding its role in plant drought tolerance (Wang et al. 2017b; Zhu et al. 2019; Harb et al. 2020). The production of ABA in the root hair and then mobilized to the leaves will maintain plant water status through stromal regulation (Zhang et al. 2018), and then postpone the development of water deficit in the aboveground (Liu et al. 2005). PP2C, PYL, and SnRK2 are the three critical components of the ABA signaling pathways; PP2C acts as a negative regulator, while SnRK2 acts as a positive regulator (Khan et al. 2019; Liang et al. 2018). In 
the present study, the decreased expression of ABA receptor genes $P Y R / P Y L$ combined with increased expression of $P P C 2$ and $S n R K 2$ is crucial for maintaining leaf water under drought-stressed conditions due to their function in stomal regulation. Notably, it was reported that salicylic acid (SA) production also affects stomatal opening, photorespiration, and antioxidant defenses before any detectable change in the relative water content (Sanchez-Martin et al. 2015). The Ethylene mediated drought stress memory was associated with increased SA signal transduction gene TGA expression in $1 \mathrm{~h}$ after subjected to drought stress but not $12 \mathrm{~h}$, which confirmed the crucial role of SA in the early stage of drought response. As a result of decreased ABA and Ethylene contents treated with seed Ethylene priming, the IAA responsive gene SAUR was significantly increased, whereas the Jasmonate ZIM-domain and ERF1/2 were significantly decreased. The identified phytohormone signals cross-talk opened promising avenues to maintain leaf water under soil water deficit.

\subsection{Transcription factor and phytohormones co-mediated for ethylene mediated drought tolerance}

The transcription factor played a central role in regulating gene responses to abiotic stress in plants (Golldack et al. 2014). The MYB, C2H2, NAC, AP2/ERF-ERF, and bHLH were identified and coupled with the soil water deficit in this study. These identified transcription factor families are well known in plants' stress tolerance (Zhang et al. 2015; Zhu et al. 2019). The present study's significant contribution is the Ethylene mediated drought tolerance transcription factors, including the NAC, AP2/ERF-ERF, bHLH, SNF2, WRKY, and $\mathrm{C}_{2} \mathrm{H}_{2}$. Recently, many transcription factors have been identified as critical players for drought tolerance. The NAC transcription factor gene TaNAC29, SNAC3, OsNAC52, and PtrNAC72 have been reported to enhance dehydration stress tolerance by modifying the ABA signal pathway, putrescine biosynthesis, and improving ROS savaging capability under drought (Huang et al. 2015; Fang et al. 2015; Wu et al. 2016). NAC-coding genes' overexpression could improve drought tolerance and be more effective when under the control of stress-responsive or tissue-specific promoters (Nakashima et al. 2014; Brasileiro et al. 2015). The transcription factor ERF has been reported to enhance osmotic tolerance by modulating the increase in stress-responsive gene expression, including MYB transcription factor, ABA synthesis gene, and photosynthesis-related genes (2010), thereby regulating shoot branching, lateral root, leaf senescence even the leaf wax accumulation (Nie et al. 2018; Ranjan et al. 2012). The bHLH transcription factor reported enhanced drought tolerance not only by regulating stomatal density, transpiration, photosynthesis, and flavonoid biosynthesis (Zhai et al. 2016; Dong et al. 2014; Wang et al. 2016), but also associating with ABA biosynthesis, JA module component, and root development (Seo et al. 2011; Li et al. 2019). The loss of function of the SWI2/SNF2 chromatin remodeling ATPase BRAHMA (BRM) causes ABA hypersensitivity during post-germination growth arrest, demonstrating the crucial role of SNF2 on drought sensitivity of plants (Han et al. 2012). In rice plants, ALT1, an Snf2 family chromatin remodeling ATPase, reported alkaline tolerance negatively through enhanced defense against oxidative stress (Guo et al. 2014). The WRKY transcription factor's biological function in abiotic stress has been reported enhancing drought tolerance by ABA synthesis, AsA accumulation, and MAPK signal (Rushton et al. 2010; Ren et al. 2010). GmWRKY13, GmWRKY21, and GmWRKY54 have been reported to play crucial roles in regulating both drought and salt tolerance of soybean (Zhou et al. 2008). In barley, the overexpression of the $\mathrm{C}_{2} \mathrm{H}_{2}$ type zinc finger member TaZFP1B resulted in an increase in drought tolerance (Cheuk et al. 2020), which can be mediated via a phytosulfokine receptor since overexpression AtPSKR1 improves growth in Arabidopsis.

\subsection{Antioxidant enzyme and osmotic adjustment co-mediated ROS savaging involved in Ethylene mediated drought tolerance}

Drought signals enable plants to slow down leaf water loss, stimulate the production of osmosis-regulating metabolites, activates the internal drought defense system to prevent the lipid oxidation of cell membrane (Singh et al. 2017; Gupta et al. 2020). The MDA content has been suggested as a marker of lipid peroxidation of the cell membrane in response to abiotic stress (Moller et al. 2007). The seed Ethylene priming reduced root hair MDA content, indicating the cell membrane's stressinduced injury was alleviated compared to the cultivars without seed ethylene priming. Lower MDA content can be mainly explained by increasing ROS savaging enzymes, osmotic adjustment, and metabolic alternation (Wang et al. 2017a; Hameed et al. 2011; Simova-Stoilova et al. 2009). The seed Ethylene priming increased SOD and CAT activities but not POD activities under water deficit. This is clear that seed Ethylene priming reduced oxidative stress by increasing ROS scavenging enzymes triggered to detoxify cells. The differently expressed genes associated with glutathione metabolism, phenylpropanoid biosynthesis, and flavonoid biosynthesis confirmed the Ethylene mediated drought tolerance associated with the internal

Page $11 / 27$ 
drought defense system. The osmolytes included the soluble sugar and proline contents, which have been reported to stabilize membranes and maintain protein structure at stressed conditions, which appears to be consistent with yield and yield stability (Singh et al. 2017; Blum 2017). A novel finding from the present study is that the seed Ethylene priming increased Proline content but significantly decreased soluble sugar content. This helps reduce the consumption of carbohydrates assimilates while maintaining osmotic balance, thereby partitioning more carbohydrates for leaf growth that would increase aboveground plant growth. Previous results reported that plant growth and photosynthesis remain affected by water deficit even though leaf cell turgor is maintained via osmotic adjustment (An-Ching and Boyer; Bouchabk et al. 2006). Seed Ethylene priming increased root hair Proline level, but not soluble sugar content explains why the root length did not increase significantly in seed ethylene priming treatment. Seed ethylene priming increases root volume that enables more $\mathrm{N}$ to accumulate in the leaves, thereby affecting light capture and biomass accumulation. Seed Ethylene priming increased root hair proline level that enhances drought tolerance by maintaining the osmotic balance of cells and ultimately helps plant recovery from drought stress. These short-term physiological changes also have a profound long-term consequence for plants' carbon budget at plant scale. The long-lasting stress memory reduced plant biomass loss by maintaining the leaf area and chlorophyll content, which further increased fertile tillers and grain number, thereby reduced yield loss under drought stress.

\subsection{DEGs involved in metabolites pathways and their expression pattern in response to drought stress}

The root is the first to encounter low soil moisture in the soil, and the transcriptome profiling of root hairs provide a good target for evaluating genes and key process underling plant adaption and tolerance to soil water deficit. Some antioxidants and osmotic regulation substances such as ascorbic acid (AsA), glutathione, glutathione, and flavonoid can be formed to effectively eliminate ROS and improve drought defense. Glutathione transferases are involved in protection under various stress conditions by detoxifying toxins, increasing oxidative stress (Singh et al. 2017). Glutathione S-transferases play a significant role under drought conditions by conjugating glutathione with electrophilic substrates to increase their solubility and facilitate further metabolic processing (Yilmaz and Iscan 2014). Expression levels of glutathione S-transferase and glutathione peroxidase activity under drought in flag leaves were found correlated with high yield stability (Galle et al. 2009). Genes encoding glutathione-disulfide reductase and glutathione peroxidase were upregulated under drought stress. In contrast, genes encoding glutathione transferase were down-regulated for both $1 \mathrm{~h}$ and $12 \mathrm{~h}$ subjected to soil drought, indicating that upregulated gene expression involved in glutathione biosynthesis was responsible for drought tolerance in plants. The antioxidant enzymes constitute the "first line of defense" against ROS-induced cell membrane peroxidation during drought stress, and the phenylpropanoids constitute a secondary antioxidant system. The phenylpropanoid biosynthesis was activated due to the depletion of primary antioxidant defenses and control cellular $\mathrm{H}_{2} \mathrm{O}_{2}$ within a sublethal concentration range (Sun et al. 2011) explained genes expression involved in phenylalanine ammonia-lyase, cinnamoyl-CoA reductase, and trans-cinnamate 4-monooxygenase were increased under drought. The catalase-peroxidase and cinnamyl-alcohol dehydrogenase were significantly decreased, which explains the decreased plant growth under drought stress. Both these findings indicate a potential role in drought stress responses of dryland winter wheat.

Seed ethylene priming induces physiological changes that affect the metabolism through the up-or down-regulation of genes involved in the phytohormone signal transduction, phenylpropanoid biosynthesis, carbon fixation, carbon metabolism, galactose metabolism. Seed ethylene priming upregulated genes related with caffeate 0-methyltransferase and peroxidase, which must have played a significant role in the seed Ethylene mediated drought stress memory. The catalase and nonspecific peroxidase activities can directly inhibit the production of $\mathrm{H}_{2} \mathrm{O}_{2}$ (Katuwal et al. 2020; Abid et al. 2018). It was speculated that seed Ethylene priming improved drought resistance related to its ability to scavenge ROS. The upregulated DEGs related to peroxidase prepared the plant response more quickly and actively to drought. It was reported that drought stress resulted in the reduction of leaf elongation by less lignin biosynthesis, which was highly corrected with the accumulation of caffeate 0-methyltransferase (Vincent et al. 2005). The caffeate 0-methyltransferase occupies a pivotal position in the phenylpropanoid pathway, which catalyzes the 0-methylation of caffeic acid to ferulic acid, a precursor of lignin polymer and a crucial component of the cell wall structure (Vincent et al. 2005; Parizotto et al. 2020). Therefore, seed 
ethylene priming increased root volume and leaf area resulted from the increased gene expression mainly involved in phenylpropanoids biosynthesis.

\subsection{Prospect for future improvement}

The short-term physiological changes do not necessarily indicate they affect the final yield (Sadras and Richards). The seed Ethylene priming avoids yield loss of $363 \mathrm{~kg} \mathrm{hm}^{-2}$ under $45 \%$ field water capacity but does not necessarily indicate they can avoid yield loss under more severe drought stress. In this investigation, the extent of yield loss by seed Ethylene priming depended on soil water availability. A significant contribution from the present study is to deepen the current knowledge on ethylene-mediated drought tolerance memory. The root-level determinations of hormone signals were made based on root hairs, while the increased water retention capability was determined on leaf levels. It is speculated that the Ethylene mediated drought tolerance was mediated by root-to-leaf cross talk. Secondly, the drought stress memory is always accompanied by wheat growth, and as approved by the present study, the final fertile spikes were significantly reduced by ethylene priming. Previous results indicated that the drought stress memory was inherited to the next generation by epigenetic modification. However, how many generations can remember this precious memory remains unknown. Thirdly, seed Ethylene priming activates genes associated with Eth sensing signals and triggers multi-hormone signals, indicating a cross-tolerance to multiple stresses condition. It is crucial to reduce the adverse effects of global climate change on crop yield. Over the past decades, researchers have made great efforts to elucidate the complex genetic architectures and a regulatory mechanism involving drought tolerance in an increasingly changing variable environment. The identified agronomy traits and genes that exert their effects on drought tolerance capability remain mostly unknown. It is of great importance to integrate multi-omics into association mapping to bridge the knowledge gap. The integration of multi-omics data will provide integrative information that increases the current knowledge of drought stress memory and multi-stress adaption. Undoubtedly, the drought tolerance improvement by using genetic approaches or seed priming, the understanding of the complex regulatory network associated with drought tolerance will help fine-tune the adaptability of wheat to withstand the challenges in an increasing changeable environment. In any case, further studies are required to shed light on (1) the exact mechanisms controlling root-to-leaf signals transduction; (2) the exact generations of the existence of the drought stress memory; (3) multi hormone signals commination adapt to cross stresses tolerance.

\section{Conclusions}

The results obtained from a combination of controlled lab experiments with observations under field drought-stressed conditions revealed that seed ethylene priming helped alleviate drought stress-induced growth inhibition by enhancing both short-term drought adaptation and long-term drought memory. Seed ethylene priming maintained leaf water by increasing root hair antioxidant enzymes and osmolytes regulation, resulting in lower membrane lipid damage than non-primed seedlings. The increased proline content and reduced soluble sugar content provided an economical approach for enhancing osmolytes regulation while realizing potential yield. The maintaining of root hair homeostasis endogenous IAA and ABA levels participates in recalling drought stress memory by affecting carbon metabolism, carbon fixation, and phenylpropanoid biosynthesis. Due to these beneficial effects, the long-lasting stress memory increased tillering capacity and florets efficiency, which provided an additional $0.3 t$ yield in the dryland farming system. Future studies on Ethylene priming-induced epigenetic modifications, transgenerational stress memory, and cross stress memory are still required to fully elucidate the role of Ethylene priming on long-term stress memory in an increasingly changing environment.

\section{Declarations}

\section{Acknowledgments}

This work was supported by the National Key Research and Development program (grant number 2016YFD0300406, 2016), The Fund of Technical Office in Sichuan Province (21YYJC1576), Special Fund for Agro-scientific Research in the public 
interest (grant number 20150312705, 2015), and Crops Breeding Project in Sichuan Province (2016NYZ0051). We thank Ms. He's helps in the field management.

\section{References}

Abid M, Hakeem A, Shao YH, Liu Y, Zahoor R, Fan YH, Jiang SY, Ata-Ul-Karim ST, Tian ZW, Jiang D, Snider JL, Dai TB (2018) Seed osmopriming invokes stress memory against post-germinative drought stress in wheat (Triticum aestivum L.). Environ Exp Bot 145:12-20. doi:10.1016/j.envexpbot.2017.10.002

Abid M, Shao Y, Liu S, Wang F, Gao J, Jiang D, Tian Z, Dai T (2017) Pre-drought priming sustains grain development under post-anthesis drought stress by regulating the growth hormones in winter wheat (Triticum aestivum L.). Planta 246 (3):509524. doi:10.1007/s00425-017-2698-4

An-Ching T, Boyer JS (2002) Growth-induced water potentials and the growth of maize leaves. J Exp Bot 368 (368):489-503

Arraes FB, Beneventi MA, Lisei de Sa ME, Paixao JF, Albuquerque EV, Marin SR, Purgatto E, Nepomuceno AL, Grossi-de-Sa MF (2015) Implications of ethylene biosynthesis and signaling in soybean drought stress tolerance. BMC Plant Biol 15:213. doi:10.1186/s12870-015-0597-z

Ashraf M (2010) Inducing drought tolerance in plants: recent advances. Biotechnol Adv 28 (1):169-183. doi:10.1016/j.biotechadv.2009.11.005

Blum A (2017) Osmotic adjustment is a prime drought stress adaptive engine in support of plant production. Plant Cell Environ 40 (1):4-10. doi:10.1111/pce.12800

Bohm W (1979) Methods of studying root systems, Ecological studies, analysis and synthesis, vol 33. Ecological studies. Analysis and synthesis. Springer-Verlag, Berlin

Bouchabk O, Tardieu F, Simonneau T (2006) Leaf growth and turgor in growing cells of maize (Zea mays L.) respond to evaporative demand under moderate irrigation but not in water-saturated soil. Plant, Cell Environ 29 (6):1138-1148

Brasileiro AC, Morgante CV, Araujo AC, Leal-Bertioli SC, Silva AK, Martins AC, Vinson CC, Santos CM, Bonfim O, Togawa RC, Saraiva MA, Bertioli DJ, Guimaraes PM (2015) Transcriptome Profiling of Wild Arachis from Water-Limited Environments Uncovers Drought Tolerance Candidate Genes. Plant Mol Biol Report 33 (6):1876-1892. doi:10.1007/s11105-015-0882-x

Castillo G, Martinez S (1997) Reversed-phase C18 high-performance liquid chromatography of gibberellins $\mathrm{GA}_{3}$ and $\mathrm{GA}_{1}$. J Chromatogr A 782 (1):137-139

Cheuk A, Ouellet F, Houde M (2020) The barley stripe mosaic virus expression system reveals the wheat $\mathrm{C} 2 \mathrm{H} 2$ zinc finger protein TaZFP1B as a key regulator of drought tolerance. BMC Plant Biol 20 (1):144. doi:10.1186/s12870-020-02355-x

Daryanto S, Wang LX, Jacinthe PA (2017) Global synthesis of drought effects on cereal, legume, tuber and root crops production: A review. Agric Water Manage 179:18-33. doi:10.1016/j.agwat.2016.04.022

Divte P, Yadav P, Jain PK, Paul S, Singh B (2019) Ethylene regulation of root growth and phytosiderophore biosynthesis determines iron deficiency tolerance in wheat (Triticum spp). Environ Exp Bot 162:1-13. doi:10.1016/j.envexpbot.2019.01.011

Dong Y, Wang C, Han X, Tang S, Liu S, Xia X, Yin W (2014) A novel bHLH transcription factor PebHLH35 from Populus euphratica confers drought tolerance through regulating stomatal development, photosynthesis and growth in Arabidopsis. Biochem Biophys Res Commun 450 (1):453-458. doi:10.1016/j.bbrc.2014.05.139 
Egea I, Albaladejo I, Meco V, Morales B, Sevilla A, Bolarin MC, Flores FB (2018) The drought-tolerant Solanum pennellii regulates leaf water loss and induces genes involved in amino acid and ethylene/jasmonate metabolism under dehydration. Sci Rep 8 (1):2791. doi:10.1038/s41598-018-21187-2

Fahad S, Bajwa AA, Nazir U, Anjum SA, Farooq A, Zohaib A, Sadia S, Nasim W, Adkins S, Saud S, Ihsan MZ, Alharby H, Wu C, Wang D, Huang J (2017) Crop Production under Drought and Heat Stress: Plant Responses and Management Options. Front Plant Sci 8:1147. doi:10.3389/fpls.2017.01147

Fang Y, Du Y, Wang J, Wu A, Qiao S, Xu B, Zhang S, Siddique KHM, Chen Y (2017) Moderate Drought Stress Affected Root Growth and Grain Yield in Old, Modern and Newly Released Cultivars of Winter Wheat. Front Plant Sci 8:672. doi:10.3389/fpls.2017.00672

Fang Y, Liao K, Du H, Xu Y, Song H, Li X, Xiong L (2015) A stress-responsive NAC transcription factor SNAC3 confers heat and drought tolerance through modulation of reactive oxygen species in rice. J Exp Bot 66 (21):6803-6817. doi:10.1093/jxb/erv386

Fang Y, Xiong $L$ (2015) General mechanisms of drought response and their application in drought resistance improvement in plants. Cell Mol Life Sci 72 (4):673-689. doi:10.1007/s00018-014-1767-0

Farooq M, Hussain M, Siddique KHM (2014) Drought Stress in Wheat during Flowering and Grain-filling Periods. Critical Reviews in Plant Sciences 33 (4):331-349. doi:10.1080/07352689.2014.875291

Galle A, Csiszar J, Secenji M, Guoth A, Cseuz L, Tari I, Gyorgyey J, Erdei L (2009) Glutathione transferase activity and expression patterns during grain filling in flag leaves of wheat genotypes differing in drought tolerance: Response to water deficit. J Plant Physiol 166 (17):1878-1891. doi:10.1016/j.jplph.2009.05.016

Golldack D, Li C, Mohan H, Probst N (2014) Tolerance to drought and salt stress in plants: Unraveling the signaling networks. Front Plant Sci 5:151. doi:10.3389/fpls.2014.00151

Guo M, Wang R, Wang J, Hua K, Wang Y, Liu X, Yao S (2014) ALT1, a Snf2 family chromatin remodeling ATPase, negatively regulates alkaline tolerance through enhanced defense against oxidative stress in rice. PLoS One 9 (12):e112515. doi:10.1371/journal.pone.0112515

Gupta A, Rico-Medina A, Cano-Delgado Al (2020) The physiology of plant responses to drought. Science 368 (6488):266-269. doi:10.1126/science.aaz7614

Hameed A, Bibi N, Akhter J, Iqbal N (2011) Differential changes in antioxidants, proteases, and lipid peroxidation in flag leaves of wheat genotypes under different levels of water deficit conditions. Plant Physiol Biochem 49 (2):178-185. doi:10.1016/j.plaphy.2010.11.009

Han SK, Sang Y, Rodrigues A, Biol F, Wu MF, Rodriguez PL, Wagner D (2012) The SWI2/SNF2 chromatin remodeling ATPase BRAHMA represses abscisic acid responses in the absence of the stress stimulus in Arabidopsis. Plant Cell 24 (12):48924906. doi:10.1105/tpc.112.105114

Harb A, Simpson C, Guo W, Govindan G, Kakani VG, Sunkar R (2020) The effect of drought on transcriptome and hormonal profiles in barley genotypes with contrasting drought tolerance. Front Plant Sci 11:618491. doi:10.3389/fpls.2020.618491

Huang Q, Wang Y, Li B, Chang J, Chen M, Li K, Yang G, He G (2015) TaNAC29, a NAC transcription factor from wheat, enhances salt and drought tolerance in transgenic Arabidopsis. BMC Plant Biol 15 (1):268. doi:10.1186/s12870-015-0644-9

Jisha KC, Vijayakumari K, Puthur JT (2013) Seed priming for abiotic stress tolerance: an overview. Acta Physiol Plant 35

(5):1381-1396. doi:10.1007/s11738-012-1186-5

Page 15/27 
Kamphorst SH, Amaral Júnior ATd, Lima VJd, Guimarães LJM, Schmitt KFM, Leite JT, Santos PHAD, Chaves MM, Mafra GS, Santos Junior DRd, Cruz CD, Campostrini E (2019) Can Genetic Progress for Drought Tolerance in Popcorn Be Achieved by Indirect Selection? Agronomy 9 (12):792. doi:10.3390/agronomy9120792

Katuwal KB, Schwartz B, Jespersen D (2020) Desiccation avoidance and drought tolerance strategies in bermudagrasses. Environ Exp Bot 171:103947. doi:ARTN 103947

10.1016/j.envexpbot.2019.103947

Kemal K (2015) Diverse roles of jasmonates and ethylene in abiotic stress tolerance. Trends Plant Sci 20 (4):219-229

Khan R, Zhou P, Ma X, Zhou L, Wu Y, Ullah Z, Wang S (2019) Transcriptome Profiling, Biochemical and Physiological Analyses Provide New Insights towards Drought Tolerance in Nicotiana tabacum L. Genes (Basel) 10 (12):27. doi:10.3390/genes10121041

Kinoshita T, Seki M (2014) Epigenetic memory for stress response and adaptation in plants. Plant Cell Physiol 55 (11):18591863. doi:10.1093/pcp/pcu125

Kolbert Z, Feigl G, Freschi L, Poor P (2019) Gasotransmitters in Action: Nitric Oxide-Ethylene Crosstalk during Plant Growth and Abiotic Stress Responses. Antioxidants (Basel) 8 (6):22. doi:10.3390/antiox8060167

Kumar M, Chauhan AS, Kumar M, Yusuf MA, Sanyal I, Chauhan PS (2019) Transcriptome Sequencing of Chickpea (Cicer arietinum L.) Genotypes for Identification of Drought-Responsive Genes Under Drought Stress Condition. Plant Mol Biol Rep 37 (3):186-203. doi:10.1007/s11105-019-01147-4

Lang DY, Fei PX, Cao GY, Jia XX, Zhang XH (2018) Silicon promotes seedling growth and alters endogenous IAA, GA3 and ABA concentrations in Glycyrrhiza uralensis under $100 \mathrm{mM} \mathrm{NaCl}$ stress. J Hortic Sci Biotechnol 94 (1):1-7

Larkunthod P, Nounjan N, Siangliw JL, Toojinda T, Sanitchon J, Jongdee B, Theerakulpisut P (2018) Physiological Responses under Drought Stress of Improved Drought-Tolerant Rice Lines and their Parents. Not Bot Horti Agrobot Cluj-Na 46 (2):679687. doi:10.15835/nbha46211188

Li CS, Li JG, Tang YL, Wu XL, Wu C, Huang G, Zeng H (2016) Stand establishment, root development and yield of winter wheat as affected by tillage and straw mulch in the water deficit hilly region of southwestern China. J Integr Agric 15 (7):1480-1489. doi:10.1016/S2095-3119(15)61184-4

Li PF, Ma BL, Palta JA, Ding TT, Cheng ZG, Lv GC, Xiong YC (2021) Wheat breeding highlights drought tolerance while ignores the advantages of drought avoidance: A meta-analysis. Eur J Agron 122:12. doi:ARTN 126196

10.1016/j.eja.2020.126196

Li X, Liu F (2016) Drought stress memory and drought stress tolerance in plants: biochemical and molecular basis. In: Drought Stress Tolerance in Plants, Vol 1, vol Vol 1. Springer, Cham, pp 17-44

Li Z, Liu C, Zhang Y, Wang B, Ran Q, Zhang J (2019) The bHLH family member ZmPTF1 regulates drought tolerance in maize by promoting root development and abscisic acid synthesis. J Exp Bot 70 (19):5471-5486. doi:10.1093/jxb/erz307

Liang CZ, Liu Y, Li YY, Meng ZG, Yan R, Zhu T, Wang Y, Kang SJ, Abid MA, Malik W, Sun GQ, Guo SD, Zhang R (2017) Activation of ABA Receptors Gene GhPYL9-11A Is Positively Correlated with Cotton Drought Tolerance in Transgenic Arabidopsis. Frontiers in Plant Science 8:1453. doi:ARTN 1453

$10.3389 /$ fpls.2017.01453

Page $16 / 27$ 
Liang Z, Li X, Li D, Sun Y, Li Y, Qin L, Liu Z, Wang J, Li X, Hong Z (2018) CARK1 mediates ABA signaling by phosphorylation of ABA receptors. Cell Discov 4 (1):30

Liu F, Jensen CR, Andersen MN (2005) A review of drought adaptation in crop plants: changes in vegetative and reproductive physiology induced by ABA-based chemical signals. Aust J Agri Res 56 (11):1245

Liu F, Shahnazari A, Andersen MN, Jacobsen SE, Jensen CR (2006) Physiological responses of potato (Solanum tuberosum L.) to partial root-zone drying: ABA signalling, leaf gas exchange, and water use efficiency. J Exp Bot 57 (14):3727-3735. doi:10.1093/jxb/erl131

Liu SX, Qin F (2021) Genetic dissection of maize drought tolerance for trait improvement. Molecular Breeding 41 (2):1-13. doi:ARTN 8

\section{$10.1007 / \mathrm{s} 11032-020-01194-\mathrm{w}$}

Miller G, Suzuki N, Ciftci-Yilmaz S, Mittler R (2010) Reactive oxygen species homeostasis and signalling during drought and salinity stresses. Plant Cell Environ 33 (4):453-467. doi:10.1111/j.1365-3040.2009.02041.x

Moller IM, Jensen PE, Hansson A (2007) Oxidative modifications to cellular components in plants. Annual Review of Plant Biology 58 (1):459-481. doi:10.1146/annurev.arplant.58.032806.103946

Muscolo A, Junker A, Klukas C, Weigelt-Fischer K, Riewe D, Altmann T (2015) Phenotypic and metabolic responses to drought and salinity of four contrasting lentil accessions. J Exp Bot 66 (18):5467-5480. doi:10.1093/jxb/erv208

Nakashima K, Yamaguchi-Shinozaki K, Shinozaki K (2014) The transcriptional regulatory network in the drought response and its crosstalk in abiotic stress responses including drought, cold, and heat. Front Plant Sci 5 (170):170

Nie J, Wen C, Xi L, Lv S, Zhao Q, Kou Y, Ma N, Zhao L, Zhou X (2018) The AP2/ERF transcription factor CmERF053 of chrysanthemum positively regulates shoot branching, lateral root, and drought tolerance. Plant Cell Rep 37 (7):1049-1060. doi:10.1007/s00299-018-2290-9

Pace J, Gardner C, Romay C, Ganapathysubramanian B, Lubberstedt T (2015) Genome-wide association analysis of seedling root development in maize (Zea mays L.). Bmc Genomics 16:47. doi:10.1186/s12864-015-1226-9

Parizotto AV, Ferro AP, Marchiosi R, Finger-Teixeira A, Bevilaqua JM, dos Santos WD, Seixas FAV, Ferrarese-Filho O (2020) Inhibition of Maize Caffeate 3-0-Methyltransferase by Nitecapone as a Possible Approach to Reduce Lignocellulosic Biomass Recalcitrance. Plant Mol Biol Rep 39 (1):179-191. doi:10.1007/s11105-020-01242-x

Pinheiro C, Chaves MM (2011) Photosynthesis and drought: can we make metabolic connections from available data? J Exp Bot 62 (3):869-882. doi:10.1093/jxb/erq340

Pouri K, Mardeh ASS, Sohrabi Y, Soltani A (2019) Crop Phenotyping for Wheat Yield and Yield Components against Drought Stress. Cereal Res Commun 47 (2):383-393. doi:10.1556/0806.47.2019.05

Quan RD, Hu SJ, Zhang ZL, Zhang HW, Zhang ZJ, Huang RF (2010) Overexpression of an ERF transcription factor TSRF1 improves rice drought tolerance. Plant Biotechnology Journal 8 (4):476-488. doi:10.1111/j.1467-7652.2009.00492.x

Ranjan A, Nigam D, Asif MH, Singh R, Ranjan S, Mantri S, Pandey N, Trivedi I, Rai KM, Jena SN, Koul B, Tuli R, Pathre UV, Sawant SV (2012) Genome wide expression profiling of two accession of G. herbaceum L. in response to drought. Bmc Genomics 13 (1):94. doi:10.1186/1471-2164-13-94

Ren X, Chen Z, Liu Y, Zhang H, Zhang M, Liu Q, Hong X, Zhu JK, Gong Z (2010) ABO3, a WRKY transcription factor, mediates plant responses to abscisic acid and drought tolerance in Arabidopsis. Plant J 63 (3):417-429. doi:10.1111/j.1365-

Page $17 / 27$ 
Rushton PJ, Somssich IE, Ringler P, Shen QJ (2010) WRKY transcription factors. Trends Plant Sci 15 (5):247-258. doi:10.1016/j.tplants.2010.02.006

Sadok W, Schoppach R (2019) Potential involvement of root auxins in drought tolerance by modulating nocturnal and daytime water use in wheat. Ann Bot 124 (6):969-978. doi:10.1093/aob/mcz023

Sadras VO, Richards RA (2014) Improvement of crop yield in dry environments: benchmarks, levels of organisation and the role of nitrogen. J Exp Bot 65 (8):1981-1995. doi:10.1093/jxb/eru061

Sairam R, Saxena D (2000) Oxidative stress and antioxidants in wheat genotypes: possible mechanism of water stress tolerance. J Agron Crop Sci 184 (1):55-61

Sanchez-Martin J, Heald J, Kingston-Smith A, Winters A, Rubiales D, Sanz M, Mur LA, Prats E (2015) A metabolomic study in oats (Avena sativa) highlights a drought tolerance mechanism based upon salicylate signalling pathways and the modulation of carbon, antioxidant and photo-oxidative metabolism. Plant Cell Environ 38 (7):1434-1452. doi:10.1111/pce.12501

Seo JS, Joo J, Kim MJ, Kim YK, Nahm BH, Song SI, Cheong JJ, Lee JS, Kim JK, Choi YD (2011) OsbHLH148, a basic helixloop-helix protein, interacts with OsJAZ proteins in a jasmonate signaling pathway leading to drought tolerance in rice. Plant J 65 (6):907-921. doi:10.1111/j.1365-313X.2010.04477.x

Seo YJ, Park JB, Cho YJ, Jung C, Seo HS, Park SK, Nahm BH, Song JT (2010) Overexpression of the ethylene-responsive factor gene BrERF4 from Brassica rapa increases tolerance to salt and drought in Arabidopsis plants. Mol Cells 30 (3):271277. doi:10.1007/s10059-010-0114-z

Shi X, Yu D, Warner E, Sun W, Petersen G, Gong Z, Lin H (2006) Cross-reference system for translating between genetic soil classification of China and soil taxonomy. Soil Sci Soc Am J 70 (1):78-83

Simova-Stoilova L, Demirevska K, Petrova T, Tsenov N, Feller U (2009) Antioxidative protection and proteolytic activity in tolerant and sensitive wheat (Triticum aestivum L.) varieties subjected to long-term field drought. Plant Growth Regul 58 (1):107-117. doi:10.1007/s10725-008-9356-6

Singh D, Singh CK, Taunk J, Tomar RS, Chaturvedi AK, Gaikwad K, Pal M (2017) Transcriptome analysis of lentil (Lens culinaris Medikus) in response to seedling drought stress. Bmc Genomics 18 (1):206. doi:10.1186/s12864-017-3596-7

Sun Y, You Y, Zhu G, Fubing LV, Dongmei LI, Chen H (2011) Effects of drought stress on activity of antioxidant enzymes and osmotic adjustment substances content in oncidium. Environ Earth Sci

Takagi H, Ishiga Y, Watanabe S, Konishi T, Egusa M, Akiyoshi N, Matsuura T, Mori IC, Hirayama T, Kaminaka H, Shimada H, Sakamoto A (2016) Allantoin, a stress-related purine metabolite, can activate jasmonate signaling in a MYC2-regulated and abscisic acid-dependent manner. J Exp Bot 67 (8):2519-2532. doi:10.1093/jxb/erw071

Tardieu F, Simonneau T, Muller B (2018) The Physiological Basis of Drought Tolerance in Crop Plants: A Scenario-Dependent Probabilistic Approach. Annu Rev Plant Biol 69:733-759. doi:10.1146/annurev-arplant-042817-040218

Tian Q, Chen F, Liu J, Zhang F, Mi G (2008) Inhibition of maize root growth by high nitrate supply is correlated with reduced IAA levels in roots. J Plant Physiol 165 (9):942-951. doi:10.1016/j.jplph.2007.02.011

Tombesi S, Nardini A, Frioni T, Soccolini M, Zadra C, Farinelli D, Poni S, Palliotti A (2015) Stomatal closure is induced by hydraulic signals and maintained by ABA in drought-stressed grapevine. Sci Rep 5:12449. doi:10.1038/srep12449 
Van Elsas J (1995) Methods of soil analysis. Part 2-Microbiological and biochemical properties: RW Weaver, Scott Angle, Peter Bottomley, David Bezdicek, Scott Smith, Ali Tabatabai and Art Wollum (editors), Soil Science Society of America, number 5 in the Soil Science Society of America Book Series, 1994, hardcover, 1121 pp., US \$65, ISBN 0-89118-810-X. Elsevier,

Vincent D, Lapierre C, Pollet B, Cornic G, Negroni L, Zivy M (2005) Water deficits affect caffeate O-methyltransferase, lignification, and related enzymes in maize leaves. A proteomic investigation. Plant Physiol 137 (3):949

Virlouvet L, Fromm M (2015) Physiological and transcriptional memory in guard cells during repetitive dehydration stress. New Phytol 205 (2):596-607. doi:10.1111/nph.13080

Wang C, Lu G, Hao Y, Guo H, Guo Y, Zhao J, Cheng H (2017a) ABP9, a maize bZIP transcription factor, enhances tolerance to salt and drought in transgenic cotton. Planta 246 (3):453-469. doi:10.1007/s00425-017-2704-x

Wang FB, Zhu H, Chen DH, Li ZJ, Peng RH, Yao QH (2016) A grape bHLH transcription factor gene, $V v b H L H 1$, increases the accumulation of flavonoids and enhances salt and drought tolerance in transgenic Arabidopsis thaliana. Plant Cell Tissue and Organ Culture 125 (2):387-398. doi:10.1007/s11240-016-0953-1

Wang N, Guo T, Wang P, Sun X, Shao Y, Jia X, Liang B, Gong X, Ma F (2017b) MhYTP1 and MhYTP2 from Apple Confer Tolerance to Multiple Abiotic Stresses in Arabidopsis thaliana. Front Plant Sci 8:1367. doi:10.3389/fpls.2017.01367

Wang W, Wang L, Wang L, Tan M, Ogutu CO, Yin Z, Zhou J, Wang J, Wang L, Yan X (2021) Transcriptome analysis and molecular mechanism of linseed (Linum usitatissimum L.) drought tolerance under repeated drought using single-molecule long-read sequencing. Bmc Genomics 22 (1):109. doi:10.1186/s12864-021-07416-5

Wang X, Mao ZQ, Zhang J, Hemat M, Huang M, Cai J, Zhou Q, Dai TB, Jiang D (2019) Osmolyte accumulation plays important roles in the drought priming induced tolerance to post-anthesis drought stress in winter wheat (Triticum aestivum L.). Environ Exp Bot 166:10. doi:ARTN 103804

10.1016/j.envexpbot.2019.103804

Wei B, Hou K, Zhang HH, Wang XY, Wu W (2020) Integrating transcriptomics and metabolomics to studies key metabolism, pathways and candidate genes associated with drought-tolerance in Carthamus tinctorius L. Under drought stress. Ind Crop Prod 151:15. doi:ARTN 112465

10.1016/j.indcrop.2020.112465

Wei H, Lv X, Yang J, Chen B, Zhao W, Meng Y, Wang Y, Zhou Z, Oosterhuis DM (2016) Effects of potassium deficiency on antioxidant metabolism related to leaf senescence in cotton ( Gossypium hirsutum L.). Field Crops Research 191:139-149

Wu H, Fu B, Sun P, Xiao C, Liu JH (2016) A NAC Transcription Factor Represses Putrescine Biosynthesis and Affects Drought Tolerance. Plant Physiol 172 (3):1532-1547. doi:10.1104/pp.16.01096

Yang H, Zhang X, Chen B, Meng Y, Wang Y, Zhao W, Zhou Z (2017) Integrated Management Strategies Increase Cottonseed, Oil and Protein Production: The Key Role of Carbohydrate Metabolism. Front Plant Sci 8:48. doi:10.3389/fpls.2017.00048

Yang HK, Wu G, Mo P, Chen SH, Wang SY, Xiao Y, Ma HLA, Wen T, Guo X, Fan GQ (2020) The combined effects of maize straw mulch and no-tillage on grain yield and water and nitrogen use efficiency of dryland winter wheat (Triticum aestivum L.). Soil Tillage Res 197:104485. doi:ARTN 104485

10.1016/j.still.2019.104485

Yilmaz C, Iscan M (2014) Glutathione S-Transferase activities and glutathione levels in needles of drought stressed Pinus Brutia Ten. trees. Turk J Biochem 39 (2):238-243. doi:10.5505/tjb.2014.88319

Page $19 / 27$ 
Zhai Y, Zhang L, Xia C, Fu S, Zhao G, Jia J, Kong X (2016) The wheat transcription factor, TabHLH39, improves tolerance to multiple abiotic stressors in transgenic plants. Biochem Biophys Res Commun 473 (4):1321-1327.

doi:10.1016/j.bbrc.2016.04.071

Zhang JY, Cruz DC, MARIA H., Torres-Jerez I, Kang Y, Allen SN, Huhman DV, Tang Y, Murray J, Sumner LW, Udvardi MK (2015) Global reprogramming of transcription and metabolism in Medicago truncatula during progressive drought and after rewatering. Plant Cell Environ 37 (11):2553-2576

Zhang Y, Zhao H, Zhou S, He Y, Luo Q, Zhang F, Qiu D, Feng J, Wei Q, Chen L, Chen M, Chang J, Yang G, He G (2018) Expression of TaGF14b, a 14-3-3 adaptor protein gene from wheat, enhances drought and salt tolerance in transgenic tobacco. Planta 248 (1):117-137. doi:10.1007/s00425-018-2887-9

Zhou QY, Tian AG, Zou HF, Xie ZM, Lei G, Huang J, Wang CM, Wang HW, Zhang JS, Chen SY (2008) Soybean WRKY-type transcription factor genes, GmWRKY13, GmWRKY21, and GmWRKY54, confer differential tolerance to abiotic stresses in transgenic Arabidopsis plants. Plant Biotechnol J 6 (5):486-503. doi:10.1111/j.1467-7652.2008.00336.x

Zhou Y, He ZH, Sui XX, Xia XC, Zhang XK, Zhang GS (2007) Genetic improvement of grain yield and associated traits in the Northern China winter wheat region from 1960 to 2000. Crop Science 47 (1):245-253. doi:10.2135/cropsci2006.03.0175

Zhu H, Zhou YY, Zhai H, He SZ, Zhao N, Liu QC (2019) Transcriptome profiling reveals insights into the molecular mechanism of drought tolerance in sweetpotato. J Integr Agric 18 (1):9-23. doi:10.1016/S2095-3119(18)61934-3

\section{Tables}

Table 1 Relative contribution to the total sum of squares (SS) and the level of significance of source of variance for 13 traits of 42 wheat genotypes grown at soil with $45 \%$ FC compared with those well-watered conditions.

\begin{tabular}{|c|c|c|c|c|c|c|c|}
\hline \multirow[t]{2}{*}{ it } & \multirow[t]{2}{*}{ Unit } & \multicolumn{2}{|c|}{ Drought } & \multirow{2}{*}{$\begin{array}{l}\text { Reduction by } \\
\text { soil water deficit }\end{array}$} & \multirow{2}{*}{\multicolumn{3}{|c|}{$\begin{array}{l}\mathrm{G} \\
\text { Contribution to the total SS }\end{array}$}} \\
\hline & & $75 \% \mathrm{FC}$ & $45 \% \mathrm{FC}$ & & & & \\
\hline \multicolumn{8}{|l|}{ its at tillering stage } \\
\hline t length & $\mathrm{cm}$ & 28.7 & 28.72 & 0.1 & $56.0^{* *}$ & 0.06 & $19.1^{* *}$ \\
\hline \multirow[t]{2}{*}{ t dry weight } & g plant ${ }^{-1}$ & 0.12 & 0.09 & 26.3 & $2.8^{* *}$ & $73.2^{* *}$ & $1.1^{\mathrm{ns}}$ \\
\hline & $\%$ & 0.18 & 0.16 & 13.2 & $3.4^{* *}$ & $28.3^{* *}$ & $1.5^{*}$ \\
\hline \multicolumn{8}{|l|}{ its at tillering stage } \\
\hline f area & - & 1.12 & 0.93 & 17.0 & $34.8^{* *}$ & $803.4^{* *}$ & $10.6^{* *}$ \\
\hline f water loss rate & $\%$ & 10.5 & 10.1 & 3.7 & $1.7^{* *}$ & 0.6 & $1.0^{\mathrm{ns}}$ \\
\hline Jrophyll content & $\mathrm{mg} \mathrm{g}^{-1}$ & 14.2 & 13.7 & 3.7 & $7.0^{* *}$ & $37.2^{* *}$ & $2.8^{* *}$ \\
\hline it biomass & g plant & 0.79 & 0.66 & 16.2 & $3.3^{* *}$ & $59.3^{* *}$ & $1.0^{\mathrm{ns}}$ \\
\hline \multicolumn{8}{|c|}{ its at maturation stage } \\
\hline it height & $\mathrm{cm}$ & 89.3 & 88.0 & 1.5 & $69.1^{* *}$ & $26.4^{* *}$ & $1.8^{* *}$ \\
\hline re length & $\mathrm{cm}$ & 10.9 & 10.4 & 4.6 & $28.5^{* *}$ & $70.9^{* *}$ & $2.0^{* *}$ \\
\hline relet & no & 18.54 & 17.5 & 5.5 & $13.6^{* *}$ & $136.3^{* *}$ & $2.2^{* *}$ \\
\hline tile tillers per plant & no & 2.96 & 2.49 & 16.0 & $16.7^{* *}$ & $480.0^{* *}$ & $10.8^{* *}$ \\
\hline icle weight & g & 2.57 & 1.94 & 24.6 & $248.2^{* *}$ & $11072.9^{* *}$ & $130.5^{* *}$ \\
\hline in yield per plant & g & 7.63 & 4.81 & 36.9 & $40.2^{* *}$ & $3395.1^{* *}$ & $29.4^{* *}$ \\
\hline
\end{tabular}

Note: $*$ and $* *$ Significant at the 0.05 and 0.01 probability levels, respectively.

G, cultivars; D, drought stress; FC, field water holding capacity.

Table 2 Seed priming effects on yield associated wheat phenotypes under soil water deficit. 


\begin{tabular}{|c|c|c|c|c|c|c|c|c|c|c|}
\hline & $\begin{array}{l}\text { Concentration } \\
\left(\mathrm{mg} \mathrm{kg}^{-1}\right)\end{array}$ & $\begin{array}{l}\text { Plant } \\
\text { height } \\
(\mathrm{cm})\end{array}$ & $\begin{array}{l}\text { Tillering } \\
\text { capacity }\end{array}$ & $\begin{array}{l}\text { Tiller } \\
\text { survival } \\
\text { rate } \\
(\%)\end{array}$ & $\begin{array}{l}\text { Fertile } \\
\text { spikes }\end{array}$ & $\begin{array}{l}\text { Fertile } \\
\text { spikelet }\end{array}$ & $\begin{array}{l}\text { Degraded } \\
\text { spikelet }\end{array}$ & $\begin{array}{l}\text { Grain } \\
\text { number }\end{array}$ & $\begin{array}{l}1000- \\
\text { kernel } \\
\text { weight } \\
\text { (g) }\end{array}$ & $\begin{array}{l}\text { Grain } \\
\text { yield } \\
\text { (kg hm } \\
\left.{ }^{2}\right)\end{array}$ \\
\hline & 200 & $83 a b c$ & $2.43 a$ & $61.6 \mathrm{a}$ & $18.5 \mathrm{ab}$ & $16.4 \mathrm{~cd}$ & $2.38 \mathrm{~b}$ & $45.0 \mathrm{bc}$ & $49.9 \mathrm{ab}$ & $6064 a$ \\
\hline & 3000 & $82 \mathrm{bcd}$ & $1.81 \mathrm{~d}$ & $61.3 \mathrm{ab}$ & $20.0 a$ & $16.7 \mathrm{bc}$ & $2.50 \mathrm{~b}$ & $47.5 \mathrm{a}$ & $50.2 \mathrm{ab}$ & $5950 \mathrm{ab}$ \\
\hline \multirow[t]{3}{*}{ de } & 100 & $84 a b$ & $2.21 \mathrm{ab}$ & $56.3 \mathrm{bc}$ & $17.2 \mathrm{bc}$ & $16.9 \mathrm{ab}$ & $2.10 \mathrm{c}$ & $46.2 \mathrm{~b}$ & $47.6 \mathrm{~b}$ & $5829 \mathrm{bc}$ \\
\hline & 0 & $82 \mathrm{~cd}$ & $2.00 \mathrm{bcd}$ & $53.7 \mathrm{c}$ & $15.8 \mathrm{c}$ & $16.1 d$ & $3.14 \mathrm{a}$ & $44.8 \mathrm{c}$ & 49.9ab & $5701 \mathrm{~cd}$ \\
\hline & 3 & $81 d$ & $2.14 \mathrm{bc}$ & $53.1 \mathrm{c}$ & $20.1 \mathrm{a}$ & $16.3 \mathrm{~cd}$ & $1.33 d$ & $45.5 \mathrm{bc}$ & $49.0 \mathrm{ab}$ & $5656 d$ \\
\hline \multirow[t]{5}{*}{ ic } & 10 & $85 a$ & $1.79 \mathrm{~d}$ & $57.9 \mathrm{abc}$ & $20.2 \mathrm{a}$ & $16.3 \mathrm{~d}$ & $2.40 \mathrm{~b}$ & $45.7 \mathrm{bc}$ & $50.3 \mathrm{ab}$ & $5489 e$ \\
\hline & 20 & $84 a b$ & $2.00 \mathrm{bcd}$ & $60.8 \mathrm{ab}$ & 18.3ab & $17.3 \mathrm{a}$ & $2.52 \mathrm{~b}$ & $47.6 \mathrm{a}$ & $52.6 a$ & $5344 \mathrm{ef}$ \\
\hline & 10 & $81 \mathrm{~cd}$ & $1.93 \mathrm{~cd}$ & $54.7 \mathrm{c}$ & $18.7 \mathrm{ab}$ & $15.5 e$ & $1.39 \mathrm{~d}$ & $43.1 \mathrm{~d}$ & $52.4 \mathrm{a}$ & $5268 f$ \\
\hline & & 83.0 & 2.04 & 57.4 & 18.6 & 16.4 & 2.22 & 45.7 & 50.2 & 5662 \\
\hline & & $5.29^{* *}$ & $8.55^{* *}$ & $5.08^{* *}$ & $5.03^{* *}$ & $12.70^{* *}$ & $80.87^{* *}$ & $14.15^{* *}$ & $1.87 \mathrm{~ns}$ & $31.74^{* *}$ \\
\hline
\end{tabular}

Table 3. Seed ethylene priming effects on above- and below-ground phenotypes of wheat grown under both well-watered (75\% FC) and drought (45\% FC) conditions.

\begin{tabular}{|c|c|c|c|c|c|c|c|c|c|c|}
\hline Treatment & $\begin{array}{l}\text { Drought } \\
\text { Stress } \\
\text { (S) }\end{array}$ & $\begin{array}{l}\text { Seedling } \\
\text { height } \\
\text { (cm) }\end{array}$ & $\begin{array}{l}\text { Shoot } \\
\text { dry } \\
\text { weight } \\
(\mathrm{mg} \\
\text { plant }^{-1} \text { ) }\end{array}$ & $\begin{array}{l}\text { Root } \\
\text { dry } \\
\text { weight } \\
(\text { mg } \\
\text { plant }^{-1} \text { ) }\end{array}$ & $\begin{array}{l}\text { Leaf } \\
\text { area } \\
\left(\mathrm{cm}^{2}\right)\end{array}$ & $\begin{array}{l}\text { Root } \\
\text { shoot } \\
\text { ratio }\end{array}$ & $\begin{array}{l}\text { Root } \\
\text { Length } \\
(\mathrm{cm})\end{array}$ & $\begin{array}{l}\text { Root } \\
\text { Surface } \\
\text { Area } \\
\left(\mathrm{cm}^{2}\right)\end{array}$ & $\begin{array}{l}\text { Root } \\
\text { Diameter } \\
(\mathrm{mm})\end{array}$ & $\begin{array}{l}\text { Root } \\
\text { Volume } \\
\left(\mathrm{cm}^{3}\right)\end{array}$ \\
\hline \multirow[t]{3}{*}{ Unpriming } & $75 \% \mathrm{FC}$ & $27.7 a$ & $37.7 \mathrm{~b}$ & $9.2 \mathrm{~b}$ & $12.5 \mathrm{~b}$ & $0.25 \mathrm{c}$ & 176.0 & $17.7 \mathrm{~b}$ & $0.33 \mathrm{~b}$ & $0.15 b$ \\
\hline & $45 \% \mathrm{FC}$ & $18.0 \mathrm{c}$ & $22.9 \mathrm{~d}$ & $9.0 \mathrm{~b}$ & $4.7 \mathrm{c}$ & $0.38 a$ & $\begin{array}{l}112.1 \\
b\end{array}$ & $12.9 \mathrm{c}$ & $0.38 a$ & $0.12 \mathrm{c}$ \\
\hline & Avg. & 22.8 & 30.3 & 9.1 & 8.6 & 0.31 & 144.0 & 15.3 & 0.35 & 0.13 \\
\hline \multirow{3}{*}{$\begin{array}{l}\text { Seed } \\
\text { ethylene } \\
\text { priming }\end{array}$} & $75 \%$ FC & $26.6 \mathrm{~b}$ & $40.4 a$ & $10.5 a$ & $13.5 a$ & $0.26 c$ & 173.8a & $18.8 \mathrm{a}$ & $0.34 b$ & $0.16 a$ \\
\hline & $45 \% \mathrm{FC}$ & $18.5 c$ & $25.9 c$ & $9.2 \mathrm{~b}$ & $5.1 \mathrm{c}$ & $0.36 \mathrm{~b}$ & $100.2 \mathrm{~b}$ & $12.6 \mathrm{c}$ & $0.40 \mathrm{a}$ & $0.12 c$ \\
\hline & Avg. & 22.6 & 33.2 & 9.9 & 9.3 & 0.31 & 137.0 & 15.7 & 0.37 & 0.14 \\
\hline \multirow[t]{3}{*}{ F-Value } & $\mathrm{P}$ & $1.2^{\mathrm{ns}}$ & $19.8^{* *}$ & $10.2^{*}$ & $24.7^{* *}$ & 0.8 & $1.9^{\mathrm{ns}}$ & $1.2^{\mathrm{ns}}$ & $2.3^{\mathrm{ns}}$ & $9.0^{*}$ \\
\hline & $\mathrm{S}$ & $1773.0^{* *}$ & $513.3^{* *}$ & $11.0^{*}$ & $2921.5^{* *}$ & $458.3^{* *}$ & $176.6^{* *}$ & $279.5^{* *}$ & $27.8^{* *}$ & $69.4^{* *}$ \\
\hline & $\mathrm{P} \times \mathrm{S}$ & $14.0^{* *}$ & $0.05^{\mathrm{ns}}$ & $0.04^{*}$ & $4.8^{\mathrm{ns}}$ & $11.0^{*}$ & $0.9^{\mathrm{ns}}$ & $4.2^{\mathrm{ns}}$ & $0.3^{\mathrm{ns}}$ & $2.8^{\mathrm{ns}}$ \\
\hline
\end{tabular}

Note: P, S, and FC represent the seed priming, soil drought, and field water holding capacity. Different letters indicate significance at the $5 \%$ probability level.

Table 4 The root hair anti-oxidative enzymes, MDA, and soluble sugar contents and plant water loss in drought compared with those under well-watered condition.

\begin{tabular}{|c|c|c|c|c|c|c|c|c|c|c|}
\hline $\begin{array}{l}\text { Primed } \\
\text { (P) }\end{array}$ & $\begin{array}{l}\text { Stress } \\
\text { (S) }\end{array}$ & $\begin{array}{l}\text { Root water } \\
\text { Content (\%) }\end{array}$ & $\begin{array}{l}\text { Leaf water } \\
\text { Content (\%) }\end{array}$ & $\begin{array}{l}\text { Root system } \\
\text { vigor (\%) }\end{array}$ & $\begin{array}{l}\text { MDA } \\
(\mu \mathrm{mol} \\
\left.g^{-1} \mathrm{DW}\right)\end{array}$ & $\begin{array}{l}\text { SOD } \\
\left(\mathrm{Ug}^{-1} \mathrm{FW}\right)\end{array}$ & $\begin{array}{l}\text { POD } \\
\left(\mathrm{g}^{-1} \mathrm{FW}\right)\end{array}$ & $\begin{array}{l}\text { CAT } \\
\left(\mathrm{g}^{-1} \mathrm{FW}\right)\end{array}$ & $\begin{array}{l}\text { Pro } \\
\left(\mathrm{mg} \mathrm{g}^{-1} \mathrm{DW}\right)\end{array}$ & $\begin{array}{l}\text { Soluble } \\
\text { sugars } \\
\left(\mathrm{mol} \mathrm{g}{ }^{-1} \mathrm{DW}\right)\end{array}$ \\
\hline \multirow[t]{3}{*}{ Unprimed } & $75 \% \mathrm{FC}$ & $95.1 \mathrm{a}$ & $89.7 a$ & $426.2 b$ & $0.22 \mathrm{c}$ & $65.48 c$ & $152.2 d$ & $57.7 \mathrm{c}$ & $2.30 \mathrm{~d}$ & $0.48 \mathrm{c}$ \\
\hline & $45 \% \mathrm{FC}$ & $93.1 \mathrm{~b}$ & $82.2 \mathrm{c}$ & 488.6ab & $0.46 a$ & $200.40 \mathrm{~b}$ & $541.0 \mathrm{a}$ & $81.4 \mathrm{a}$ & $9.59 \mathrm{~b}$ & $2.68 \mathrm{a}$ \\
\hline & Avg. & 94.1 & 85.95 & $457.4 a$ & 0.34 & 132.94 & 346.6 & 69.6 & 5.94 & 1.58 \\
\hline \multirow[t]{3}{*}{ Primed } & $75 \% \mathrm{FC}$ & $94.5 \mathrm{a}$ & $89.9 a$ & $434.2 \mathrm{~b}$ & $0.18 \mathrm{~d}$ & $50.59 \mathrm{c}$ & $277.8 \mathrm{c}$ & $47.8 \mathrm{~d}$ & $2.33 \mathrm{c}$ & $0.50 \mathrm{c}$ \\
\hline & $45 \% \mathrm{FC}$ & $93.2 \mathrm{~b}$ & $83.0 \mathrm{~b}$ & $558.1 \mathrm{a}$ & $0.36 \mathrm{~b}$ & $251.43 a$ & $412.2 \mathrm{~b}$ & $67.2 \mathrm{~b}$ & $9.93 a$ & $2.27 \mathrm{~b}$ \\
\hline & Avg. & 93.8 & 86.5 & $496.2 \mathrm{a}$ & 0.27 & 151.01 & 345.0 & 57.5 & 6.13 & 1.38 \\
\hline \multirow[t]{3}{*}{ F-Value } & $\mathrm{P}$ & $1.83^{\mathrm{NS}}$ & $9.57 *$ & $1.6^{\mathrm{NS}}$ & $22.3^{* *}$ & 6.99* & $0.02^{\mathrm{NS}}$ & $27.5^{* *}$ & $1055^{* *}$ & $13.9 * *$ \\
\hline & $\mathrm{S}$ & $58.8^{* *}$ & $1824.4^{* *}$ & $9.4^{* *}$ & $180.2^{* *}$ & $603 * *$ & $646.1^{* *}$ & $87.7^{* *}$ & $1642570 * *$ & $1486.5^{* *}$ \\
\hline & $\mathrm{P} \times \mathrm{S}$ & $3.6^{\mathrm{NS}}$ & $3.68^{\mathrm{NS}}$ & $1.0^{\mathrm{NS}}$ & 2.95 & $23.2^{* *}$ & $152.8^{* *}$ & $0.9^{\mathrm{NS}}$ & $700 * *$ & $17.5^{* *}$ \\
\hline
\end{tabular}


Note: P, S, and FC represent the seed priming, soil drought, field water holding capacity. Different letters indicate significance at the $5 \%$ probability level.

\section{Figures}
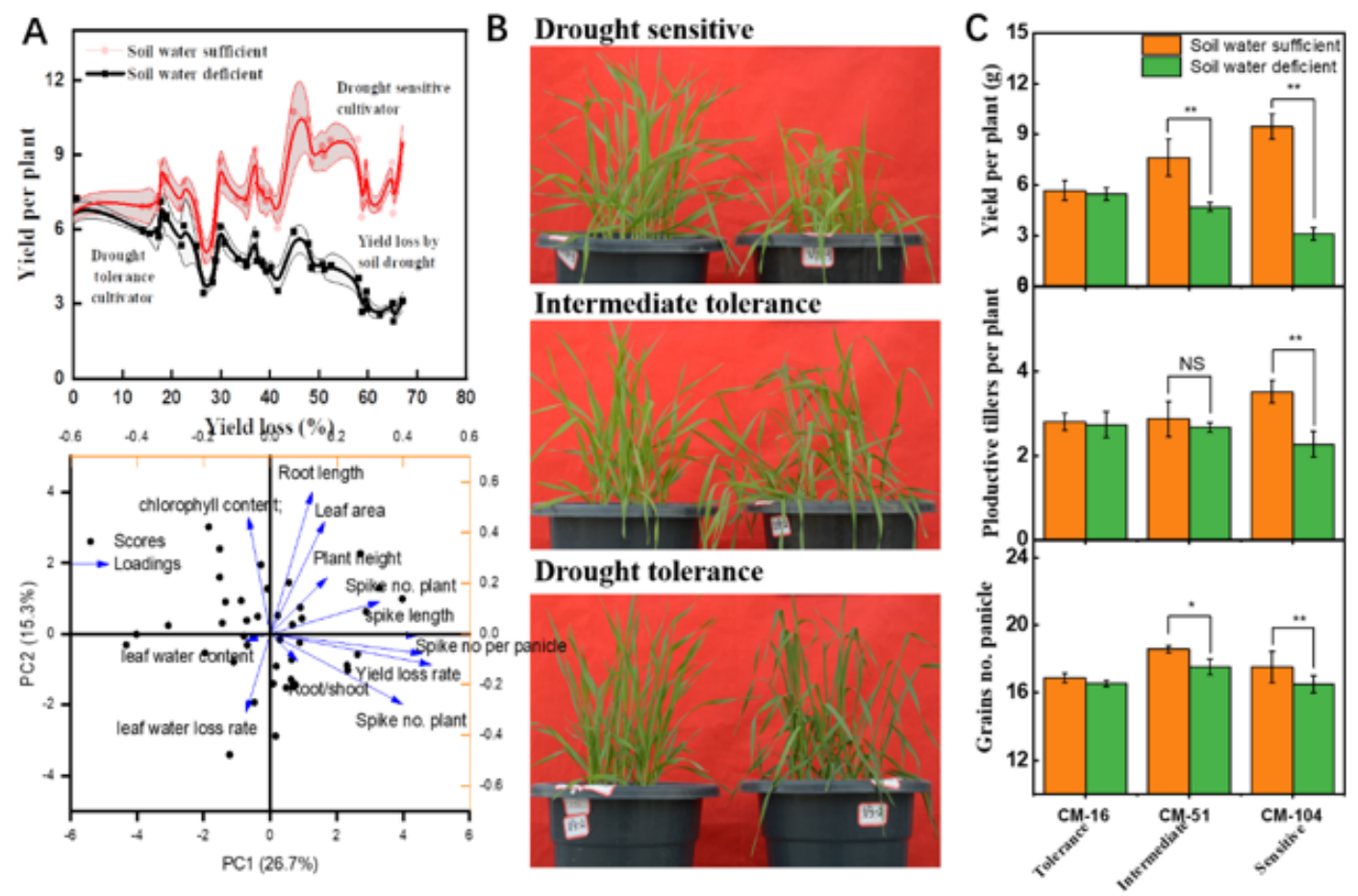

\section{Figure 1}

Phenotypes of drought resistance of 42 leading and new wheat cultivars released between 1965 and 2017 grown under both well-watered $(75 \% \mathrm{FC})$ and drought $(45 \% \mathrm{FC})$ conditions. (A) Screening of promising cultivars and their drought avoidance traits in both well water and drought conditions. (B) Comparisons of 3 cultivars with contrasting drought resistance grown under well-watered (left) and drought conditions (right). (C) Grain yield and yield components of drought sensitivity, tolerance, and intermediate cultivars were grown under drought-stressed ( $45 \% \mathrm{FC})$ and well-watered conditions ( $75 \% \mathrm{FC})$. Each column represents mean \pm S.D. (four replicates). 


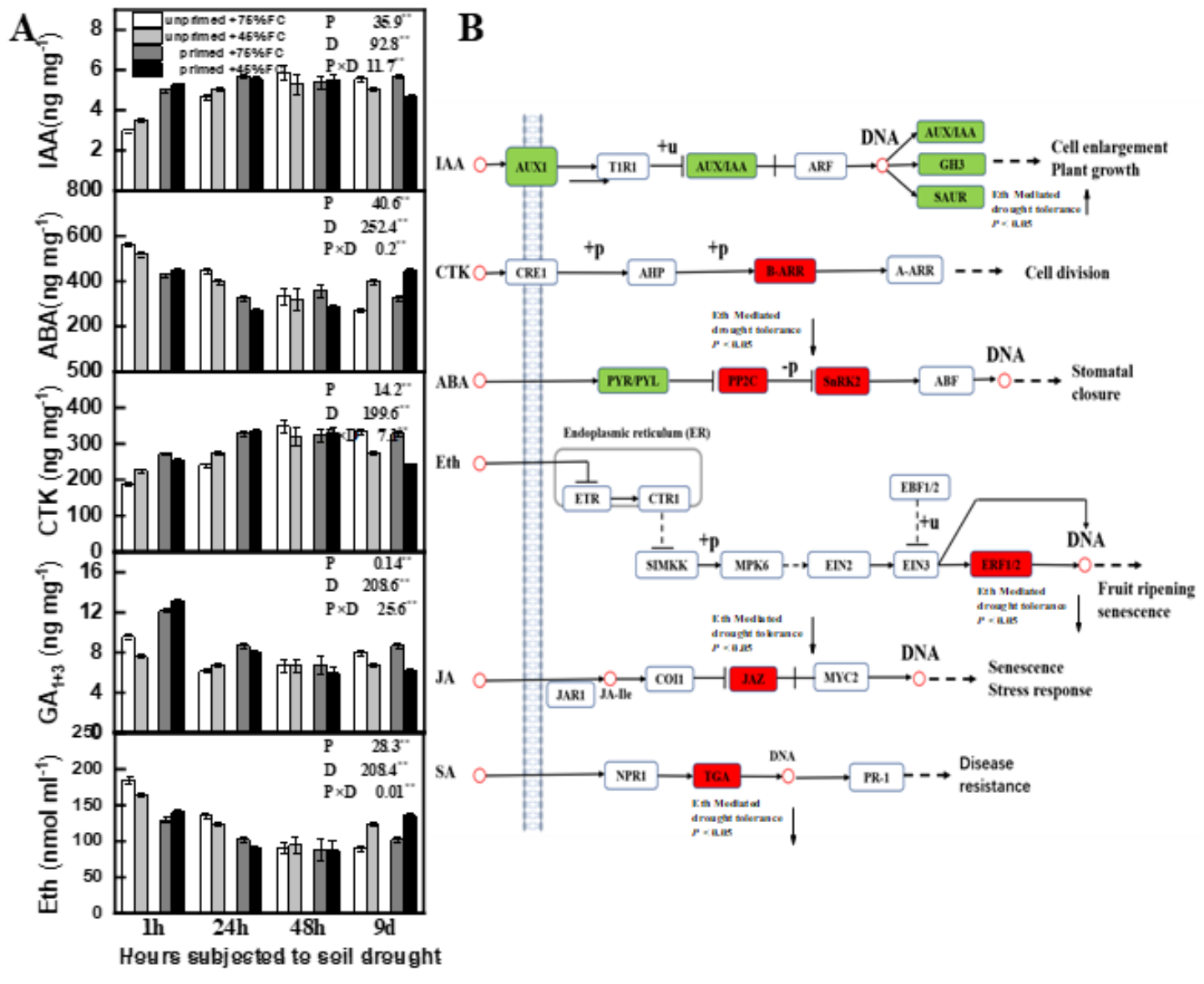

Figure 2

The changes in root hair hormone contents $(A)$ and hormone signal transduction pathways $(B)$ of seedlings primed with ethylene grown under well-watered $(75 \% \mathrm{FC})$ and drought stress $(45 \% \mathrm{FC})$ conditions. 

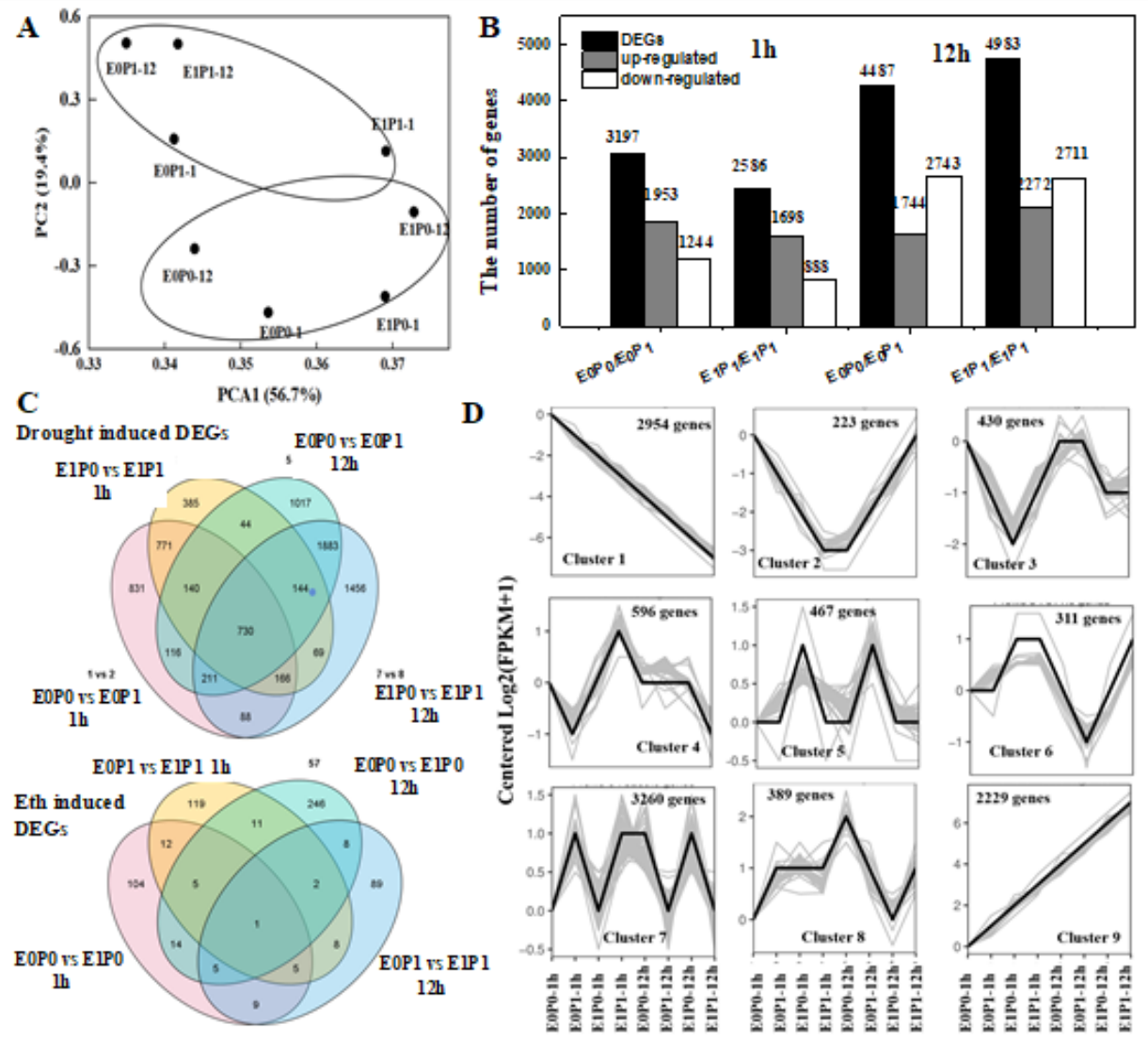

\section{Figure 3}

The differently expressed genes (DEGs), satisfying the criteria of $p \leq 0.01$, identified from drought response and ethylene mediated drought response. The $\geq 2$-fold change transcripts were used for the time series analysis 


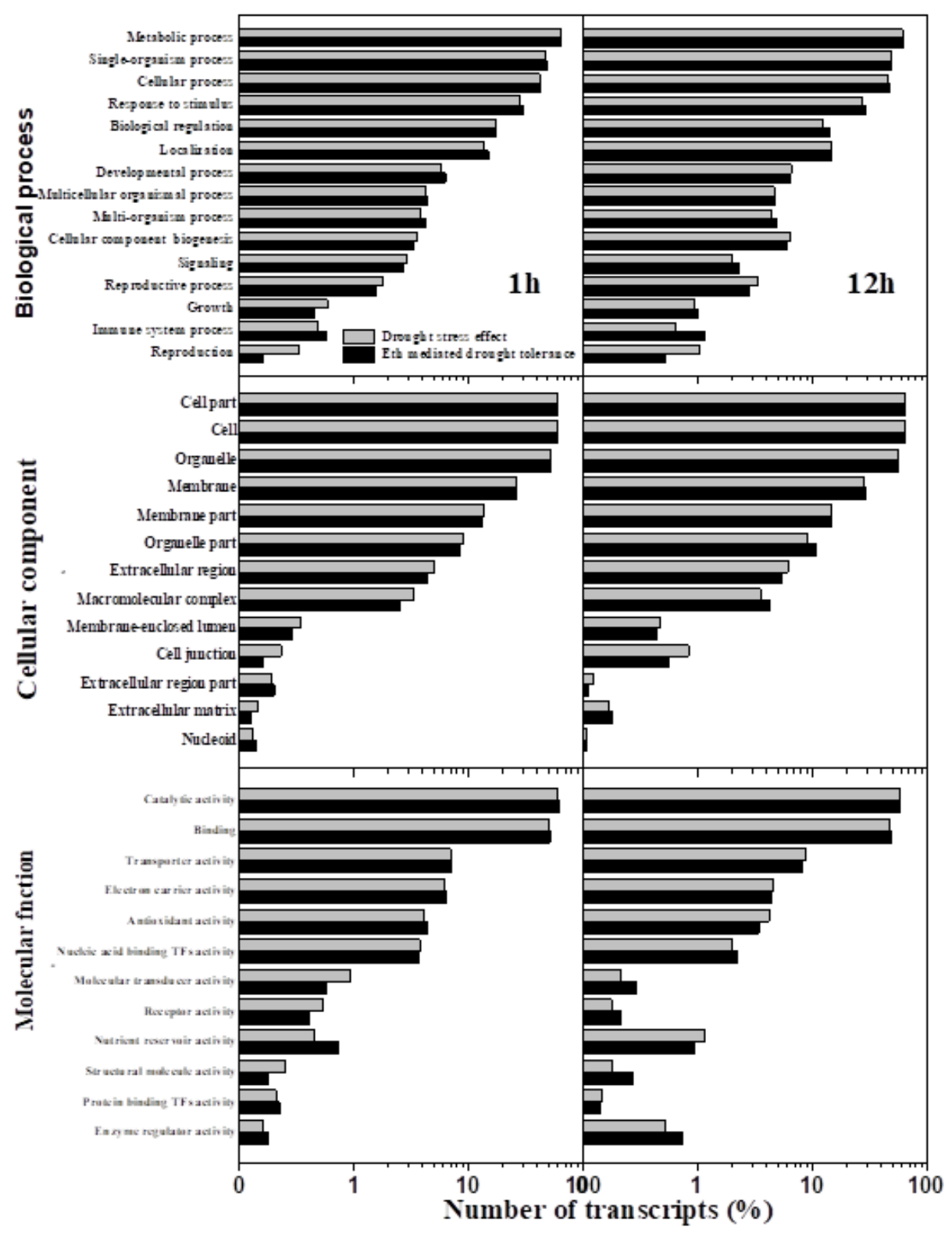

Figure 4

Gene ontology (GO) term assignment to the transcripts of primed and control plants exposed to $12 \mathrm{~h}$ of drought stress in different categories of biological process, cellular component, and molecular function in the EOP0 vs. EOP1 and EOP1 vs. E1P1 samples. The X-axis shows the percentage of transcripts associated with the enriched GO terms. 
Drought stress related pathways

A

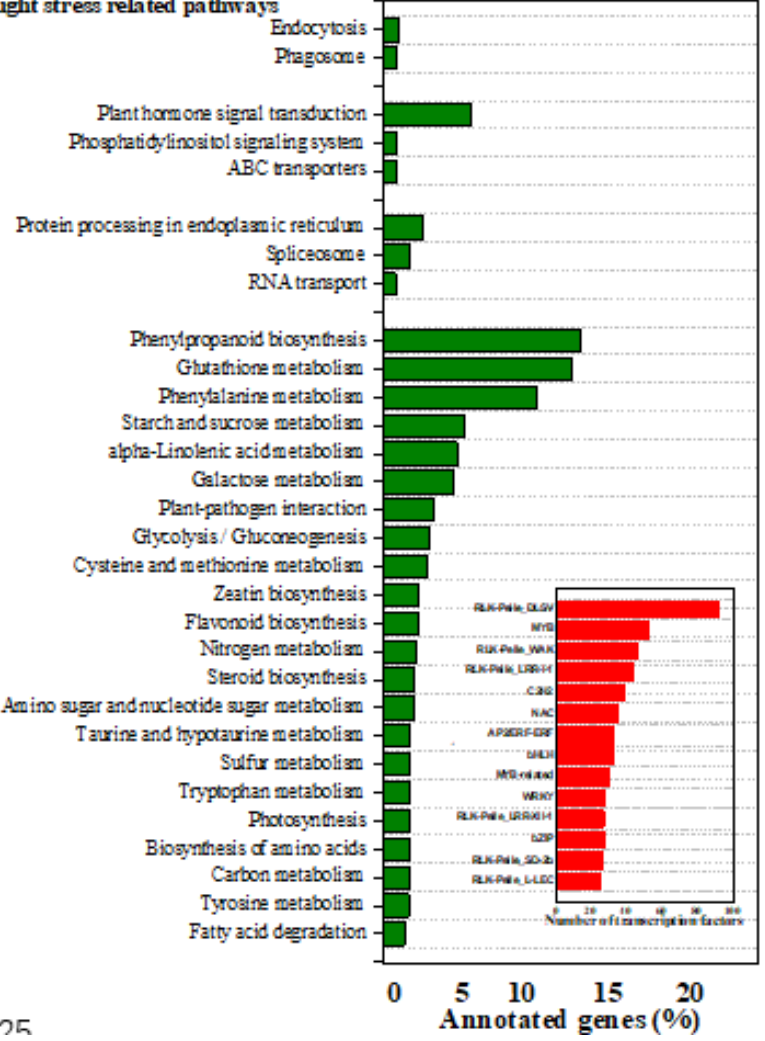

E th mediated drought tolerancepathways

B

Percrisome

Phagorome

Plant hom one signal transduction $A B C$ transporters

Spliceosone RNA transport

Carbon metabolizm Carbon fixation in photosynthetic organisms Ghuthione metabolizn Phenylpropanoid biosynthesis

Plant-pathogen interaction Gyoxylate and dicarboxylate metabolizn Amino suger and nucleotide sugar metabolizn Photorynthesis

Biosynthesis of amino acids Benzor azinoid biosynthesis Pentose phosphate pathway

aridative phosphorylation Gycolysis/ Gluconeogenesis Galactose metabolizn Starch and sucrose metabolism Photosynthesis - antenna proteins alpha-Linolenic acid metabolizn Prine matabolizn Tryptophan metabolizm Sulfur metabolizn Isoguinoline atkaloid biosynthesis

Sphingolipid metabolizn Nitrogen metabolizm irogen atabolion

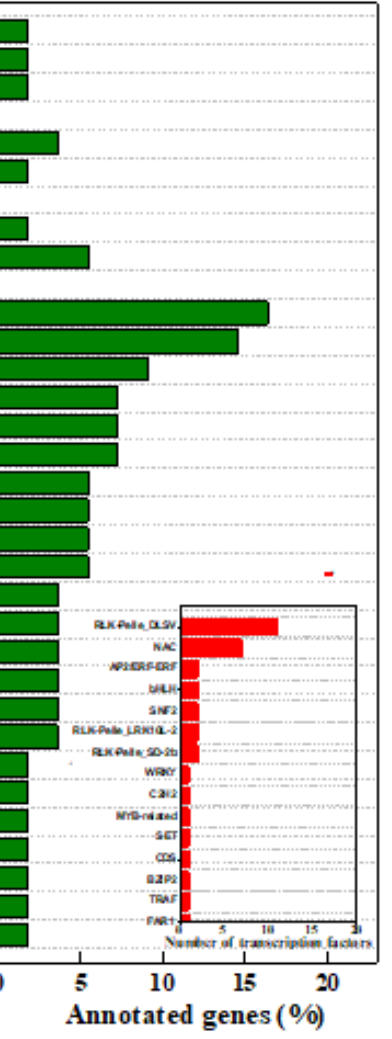

Figure 5

Top pathway entries of the DEGs related to drought response (A), and seed ethylene (Eth) priming mediated drought response (B).

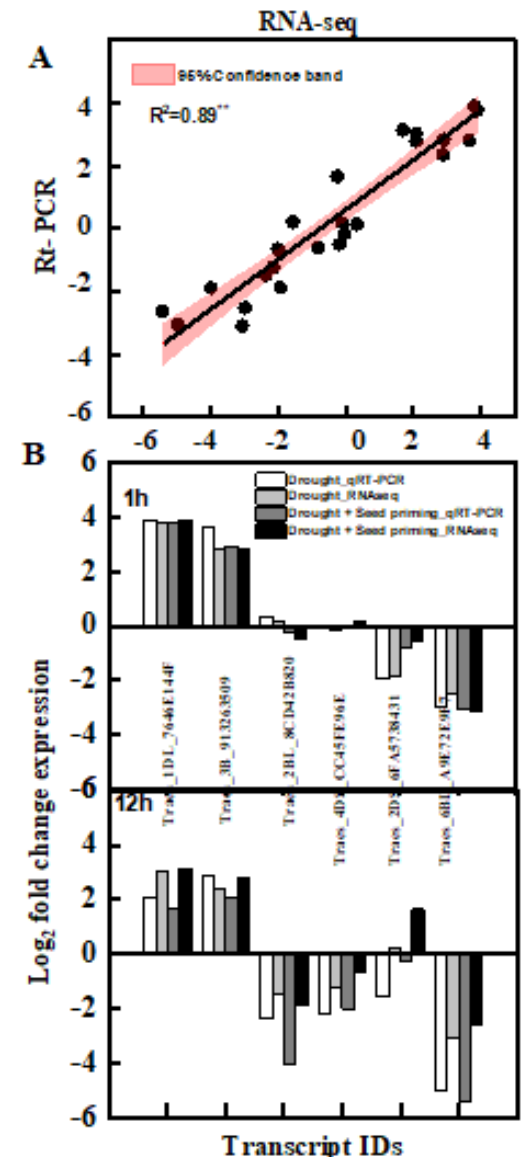




\section{Figure 6}

Validation of RNA-Seq data using quantitative real-time polymerase chain reaction (qPCR). Bar graphs depict selected transcripts' expression patterns for both primed and CK plants under well water and drought stress conditions. All the data points are represented by the log 2 fold change in the values.

\section{Supplementary Files}

This is a list of supplementary files associated with this preprint. Click to download.

- Supplementalfile.docx 